\title{
ARTICLE
}

Received 3 Nov 2015 | Accepted 22 Dec 2015 | Published 2 Feb $2016 \quad$ DOI: 10.1038/ncomms10529 OPEN

\section{RAG2 and XLF/Cernunnos interplay reveals a novel role for the RAG complex in DNA repair}

Chloé Lescale ${ }^{1}$, Vincent Abramowski ${ }^{2}$, Marie Bedora-Faure ${ }^{1}, V^{2}$ alentine Murigneux ${ }^{1}$, Gabriella Vera ${ }^{2}$, David B. Roth ${ }^{3}$, Patrick Revy ${ }^{2}$, Jean-Pierre de Villartay ${ }^{2, \star} \&$ Ludovic Deriano ${ }^{1, \star}$

XRCC4-like factor (XLF) functions in classical non-homologous end-joining (cNHEJ) but is dispensable for the repair of DNA double-strand breaks (DSBs) generated during $V(D)$ J recombination. A long-standing hypothesis proposes that, in addition to its canonical nuclease activity, the RAG1/2 proteins participate in the DNA repair phase of $V(D) J$ recombination. Here we show that in the context of RAG2 lacking the $\mathrm{C}$-terminus domain (Rag2 ${ }^{C / C}$ mice), XLF deficiency leads to a profound lymphopenia associated with a severe defect in $V(D) J$ recombination and, in the absence of p53, increased genomic instability at $V(D) J$ sites. In addition, $\operatorname{Rag}^{c / c} X \mathrm{XF}^{-/-} p 53^{-/-}$mice develop aggressive pro-B cell lymphomas bearing complex chromosomal translocations and gene amplifications involving Igh and c-myc/pvt1 loci. Our results reveal an unanticipated functional interplay between the RAG complex and XLF in repairing RAG-induced DSBs and maintaining genome integrity during antigen receptor gene assembly.

\footnotetext{
${ }^{1}$ Departments of Immunology and Genomes and Genetics, Institut Pasteur, CNRS-URA 1961, Paris 75015, France. ${ }^{2}$ Laboratory of Genome Dynamics in the Immune System, INSERM UMR1163, Université Paris Descartes Sorbonne Paris Cité, Institut Imagine, Paris 75015, France. ${ }^{3}$ Department of Pathology and Laboratory Medicine, University of Pennsylvania, Philadelphia, Pennsylvania 19104, USA. ${ }^{\star}$ Co-senior authors. Correspondence and requests for materials should be addressed to L.D. (email: ludovic.deriano@pasteur.fr).
} 
$\mathrm{B}$ and $\mathrm{T}$ lymphocyte development relies on the assembly of immunoglobulin (Ig) and T-cell receptor (TCR) variable exons from variable (V), diversity (D) and joining (J) gene segments via a cut-and-paste mechanism termed V(D)J recombination ${ }^{1}$. This process occurs in developing lymphocytes during the G1 phase of the cell cycle, and is initiated when the recombination-activating gene products RAG1 and RAG2 (forming the RAG endonuclease) introduce double-strand breaks (DSBs) between V, D or J coding gene segments and flanking recombination signal sequences (RSSs) ${ }^{2}$. RAG-mediated cleavage at a pair of RSSs generates four broken DNA ends: two blunt $5^{\prime}$ phosphorylated signal ends, which terminate in the RSS, and two covalently sealed (hairpin) coding ends. After cleavage, the RAG proteins stay associated with the DNA ends in a so-called post-cleavage complex (PCC $)^{2}$. Subsequently, the classical non-homologous end-joining pathway (cNHEJ) joins these DNA ends in a recombinant configuration, forming a coding joint (CJ) (the rearranged antigen receptor gene) and a reciprocal signal joint ${ }^{3-5}$.

RAG-induced DNA breaks activate the Ataxia telangiectasia mutated (ATM) kinase-dependent DNA damage response $(\mathrm{DDR})^{6}$. ATM-dependent p53 phosphorylation mediates the G1/S checkpoint that arrests or eliminates cells with unrepaired DSBs. ATM also phosphorylates chromatin- and/or DNAassociated proteins, including the histone variant $\mathrm{H} 2 \mathrm{AX}$ (forming $\gamma \mathrm{H} 2 \mathrm{AX}$ ), p53 binding protein 1 (53BP1), mediator of DNA damage checkpoint 1 (MDC1) and factors of the MRE11 complex (MRE11, RAD50 and NBS1) that assemble over large DNA regions of the chromatin on both sides of DNA breaks to form so-called nuclear DNA repair foci. ATM-dependent DDR, beyond activating checkpoints, may contribute to DSB repair through stabilization of DNA ends. Because the stabilization function of ATM depends on its kinase activity, formation of ATM-dependent DNA repair foci has been proposed to stabilize/ tether DNA ends for proper joining via cNHEJ. In fact, in ATM-deficient cells undergoing V(D)J recombination, a fraction of coding ends evade from the PCC and are occasionally joined aberrantly forming hybrid joints ( $\mathrm{HJs}$ ) (atypical nonproductive rearrangements formed by the ligation of a signal end to a coding end) or chromosomal deletions, inversions and translocations ${ }^{6,9}$. Despite these defects, ATM-deficient cells are still able to perform robust $\mathrm{V}(\mathrm{D}) \mathrm{J}$ recombination and ATM-deficient mice are only moderately immune-deficient. Similarly, deficiency of H2AX or 53BP1 has no demonstrable effect on the repair of RAG-mediated DSBs, indicating that other accessory proteins might compensate impaired ATM-DDR functions during the repair of RAG-DNA breaks $^{6,8}$.

During cNHEJ repair ${ }^{3}$, the Ku70/80 heterodimer $(\mathrm{Ku})$ binds DNA ends and recruits the DNA-dependent protein kinase catalytic subunit (DNA-PKcs) to form the DNA-PK holoenzyme. DNA-PK phosphorylates multiple substrates, promoting synapsis of DNA ends and facilitating the recruitment of end processing and ligation enzymes. One such enzyme is the Artemis endonuclease that carries out hairpin opening at coding ends and prepares them for joining. Finally, the XRCC4-like factor (XLF)-Ligase IV complex performs ligation of DNA ends. In mice, deficiency for cNHEJ factors (except XLF, see below) results in severe combined immunodeficiency owing to the inability to complete repair of RAG-DNA breaks. In addition, cNHEJdeficient mice that are also deficient for p53 characteristically develop pro-B cell lymphomas harbouring RAG-dependent translocations and gene amplification involving the Igh and $c-m y c$ loci (or $n-m y c$ in the case of Artemis deficiency) ${ }^{3-5}$.

XLF (also called Cernunnos or NHEJ1) was identified through both cDNA complementation of cells derived from an IR-sensitive immunodeficient patient $^{9}$ and through a yeast two-hybrid screen for XRCC4-interacting partners ${ }^{10}$. XLF and XRCC4 are two distantly related members of the same protein family and share structural similarity ${ }^{11-13}$. Together, they form long filaments, thought to help DNA end tethering during repair ${ }^{14-18}$. In contrast to other cNHEJ-deficient mice, XLF-deficient mice are not markedly immune-deficient and pro-B cell lines derived from these animals perform nearly normal $\mathrm{V}(\mathrm{D}) \mathrm{J}$ recombination ${ }^{19,20}$. In addition, XLF/p53-deficient animals, unlike other cNHEJ/p53 double-deficient mice, rarely die of pro-B cell lymphomas but instead develop T-cell lymphomas characteristic of p53 deficiency ${ }^{20}$. These results are consistent with normal overall $\mathrm{V}(\mathrm{D}) \mathrm{J}$ recombination in developing XLF-deficient lymphocytes and led to the speculation that lymphocyte-specific factors/pathways compensate for XLF function during $\mathrm{V}(\mathrm{D}) \mathrm{J}$ recombination ${ }^{3,19,20}$. This is supported by analysis of $\mathrm{V}(\mathrm{D}) \mathrm{J}$ recombination in cells deficient for both ATM-dependent DDR and XLF ${ }^{8}$. A combined deficiency of ATM, 53BP1 or H2AX with XLF deficiency results in a severe block in lymphocyte development with a significant defect in the repair of RAG-mediated DSBs, indicating functional redundancy between XLF and ATM-DDR factors during V(D)J recombination ${ }^{8,21}$. Importantly, although single deficiencies for XLF or individual DDR factors generally have little effect on $\mathrm{V}(\mathrm{D}) \mathrm{J}$ recombination, these deficiencies have been demonstrated to have a profound effect on non-V(D)J cNHEJ-mediated DSB repair (for example, irradiation or activation-induced cytidine deaminase (AID)-induced DSBs during the process of class switch recombination $)^{8,22}$, indicating that such compensatory functions are specific to the repair of RAG-mediated DNA breaks. The nature of the mechanism(s) underlying these discrepancies is unknown.

One major difference between genotoxic- or AID-induced DSBs and those occurring during $\mathrm{V}(\mathrm{D}) \mathrm{J}$ recombination is the participation of the RAG complex in the latter ${ }^{3,23}$. After cleavage in vitro, the RAG proteins remain associated with the DNA ends in a PCC, providing evidence for a potential layer of regulation at the joining step ${ }^{2}$. Separation of function mutants of RAG1 and RAG2 that are capable of cleavage in vitro but exhibit defects in performing $\mathrm{V}(\mathrm{D}) \mathrm{J}$ recombination of episomal substrates in vivo provided further evidence that the RAG PCC might serve a crucial function in joining coding and signal ends ${ }^{23-27}$. In addition, studies showed that certain RAG mutations that cause destabilization of the RAG PCC in vitro correlates with abnormal repair by homologous recombination and alternative NHEJ in vivo ${ }^{3,28-32}$. These results led to a model in which the quite stable RAG PCC, through an unknown mechanism, shepherds DNA ends to the cNHEJ machinery for repair, thus protecting them from error-prone end-joining pathways and aberrant recombination events. In that regard, a truncated RAG2 lacking the C-terminus (core RAG2: amino acids 1-352 (refs 33,34)) is of particular interest. The RAG2 C-terminus contains a flexible acidic hinge, a plant homeodomain capable of recognizing histone $\mathrm{H} 3 \mathrm{~K} 4$ trimethylation and a cell cycle-regulated protein degradation signal ${ }^{35}$. While dispensable for overall $V(D) J$ recombination, this region is important for $\mathrm{V}(\mathrm{D}) \mathrm{J}$ recombination efficiency and fidelity ${ }^{34-38}$. Core RAG2 destabilizes the RAG-PCC in vitro and increases the rate of aberrant recombination product formation in vivo $29-31,36,37,39$. Additionally, core RAG2 knockin/p53-deficient mice develop aggressive thymic lymphomas bearing complex translocations involving $T c r$ and $I g$ loci ${ }^{30}$, a phenotype reminiscent of ATM-deficient mice ${ }^{7,40}$. These results suggested that comparable RAG-PCC defects might underlie genomic instability and lymphomagenesis in $\operatorname{Rag}^{\mathrm{c} / \mathrm{c}} \mathrm{p53^{-/-^{- } } \text { and } \mathrm { Atm }}{ }^{-/-}$mice $\mathrm{e}^{30}$. Altogether, these biochemical, genetic and in vivo studies have raised the intriguing possibility that, in addition to their primary 
role in DNA cleavage at RSSs, the RAG1 and RAG2 proteins might be implicated in the joining step of $\mathrm{V}(\mathrm{D}) \mathrm{J}$ recombination. To explain the paradoxical observation that we and others have made on the normal V(D)J recombination in $X L F^{-/-}$mice ${ }^{19,20}$, we hypothesized a direct role for the RAG proteins in the repair of chromosomal RAG-DSBs ${ }^{3,19}$. In this study, we identify overlapping functions between the RAG complex and XLF in $\mathrm{V}(\mathrm{D}) \mathrm{J}$ recombination, lymphocyte development and maintenance of genome stability.

\section{Results}

Core RAG2/XLF-deficient mice are lymphopenic. To elucidate whether the RAG complex has overlapping functions with XLF and/or ATM during lymphocyte development, we bred $R a g 2^{c / c}$ mice $30,33,34$ with $X L F^{-/}-$mice $^{19}$ and $A t m^{-/-}$mice $^{30,41}$ to generate $\mathrm{Rag}^{c / c} \mathrm{XLF}^{-/-}$mice and $\mathrm{Rag}^{c / c} \mathrm{Atm}^{-/-}$mice. Consistent with previous reports ${ }^{19-21,30,34}, \operatorname{Rag}^{c / c}, X L F^{-/-}$ and $A \mathrm{tm}^{-/-}$mice displayed only partial blocks in $\mathrm{B}$ and $\mathrm{T}$ lymphopoiesis associated with a reduction in splenocyte numbers (Fig. 1 and Supplementary Fig. 1). In sharp contrast, $\mathrm{Rag}^{\mathrm{c} / c} \mathrm{XLF}^{-/-}$mice had extremely low numbers of splenocytes associated with an almost complete absence of mature $\mathrm{CD}_{19}{ }^{+} \mathrm{IgM}^{+}$splenic B cells (Fig. 1b,c) and significantly fewer mature $\mathrm{CD}^{+}{ }^{+} \mathrm{TCR} \beta^{+}$splenic $\mathrm{T}$ cells (Fig. 1d,e). Analysis of bone marrow B-cell development in $\mathrm{Rag}^{\mathrm{c} / \mathrm{c}} \mathrm{XLF}^{-/-}$mice revealed a severe block at the $\mathrm{CD}_{4}{ }^{+} \mathrm{B} 220^{\text {low }} \mathrm{CD} 19^{+} \mathrm{IgM}^{-}$ progenitor (pro-) B-cell stage during which V(D)J recombination is initiated, as shown by the near absence of $\mathrm{CD}^{2} 3^{-} \mathrm{B} 220^{\text {low }} \mathrm{CD} 19^{+} \mathrm{IgM}^{-}$precursor (pre-) B cells and $\mathrm{IgM}^{+}$ B cells (Fig. 1b,c). Rag2 ${ }^{c / c} X L F^{-/-}$mice also had very low numbers of total thymocytes (Fig. 1a), associated with a significant increase in the percentage of $\mathrm{CD}^{-} \mathrm{CD} 8^{-}$doublenegative cells that initiate $\mathrm{V}(\mathrm{D}) \mathrm{J}$ recombination (Fig. 1d). In contrast to B cells, T-cell development was not completely abolished in $\mathrm{Rag}^{\mathrm{c} / \mathrm{c}} \mathrm{XLF} \mathrm{F}^{-/-}$mice (Fig. 1d,e). This "leaky" T-cell phenotype was previously observed in $\mathrm{XLF}^{-1}-\mathrm{Atm}^{-/} \mathrm{mice}^{21}$ and other cNHEJ-deficient mice ${ }^{42,43}$. Interestingly, in contrast to $\operatorname{Rag}^{c / c} \mathrm{XLF}^{-/-}$mice, $\operatorname{Rag}^{c / c} \mathrm{Atm}^{-1-}$ mice displayed almost normal B- and T-cell development and lymphoid organ cellularity as compared with single mutant mice (Supplementary Fig. 1). Thus, although the combined deficiency in RAG2 and ATM does not severely affect B- and T-cell differentiation, core RAG2/XLF deficiency severely compromises lymphocyte differentiation at a progenitor cell stage.

Impaired Igk rearrangement in $\operatorname{Rag}^{c / c} X_{L F}^{-/-}$pro-B cells. To identify the cause of impaired lymphoid development in $\operatorname{Rag}^{c / c} X L F^{-/-}$mice, we analyzed $\mathrm{V}(\mathrm{D}) \mathrm{J}$ recombination in viral-Abelson kinase $(v-a b l)$ transformed pro-B cell lines generated from wild type (WT), Rag2 $2^{c / c}, X L F^{-/-}, \operatorname{Rag}^{c / c}$ $\mathrm{XLF}^{-/-}$and Ku80-deficient $\left({\mathrm{Ku} 80^{-}}^{-}\right)$mice. Treatment of $v$-abl transformed pro-B lines with a $v$-abl kinase inhibitor (PD180970 or STI571, hereafter named ABLki) leads to G1 cell cycle arrest, the rapid induction/stabilization of RAG1/2 gene expression and rearrangement of the Igk locus or any introduced $\mathrm{V}(\mathrm{D}) \mathrm{J}$ recombination reporter substrate $\mathrm{e}^{7,44}$. Induction of RAG in WT, $\operatorname{Rag} 2^{c / c}$, and to a lesser extent $X L F^{-/}-$pro-B cells triggered $V k$-to-J $J$ rearrangement at the endogenous I $g k$ locus, as evidence by Southern blotting revealing hybridizing bands of diverse sizes from rearrangements between $\sim 150 \mathrm{Vk}$ gene segments and the four functional $J k$ gene segments from the mouse locus (Fig. 2a,b and Supplementary Fig. 2) and by PCR analysis of inversional $I g k V_{6-23} J_{1}$ revealing CJ formation (Fig. $2 \mathrm{c}, \mathrm{d}$ ). Induction of RAG in $\mathrm{Ku}_{80} 0^{-}-$pro-B cells led to the accumulation of unrepaired coding ends at the four $J k$ segments (Fig. 2a,b and Supplementary
Fig. 2) and absence of $V k_{6-23}-J k_{1}$ CJs (Fig. 2c,d) as a result of the function of $\mathrm{Ku}$ in coding and signal joint formation ${ }^{45}$. Notably, nested PCR amplification of inversional $\operatorname{Ig} k V_{6-23}-J_{1}$ rearrangement revealed the formation of $\mathrm{HJs}$ in WT cells treated with the ATM kinase-specific inhibitor KU-55933 (ATMki) and in $R a g 2^{c / c}$ cells (Fig. 2c,d), consistent with a role for the RAG complex and ATM in stabilizing cleaved DNA ends ${ }^{7,30}$. Strikingly, HJs were also readily detected in $X L F^{-/-}$cells (Fig. 2c,d), indicating that although XLF is dispensable for $V(D) J$ recombination, it might participate in the stabilization of

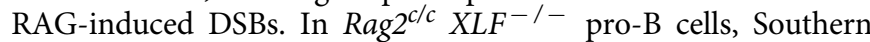
blotting revealed faint hybridizing bands of sizes corresponding to unrepaired coding ends (Fig. 2a,b and Supplementary Fig. 2) and PCR amplification revealed an almost complete lack of CJ and HJ formation (Fig. 2c,d). These results suggest a specific end-joining defect in the absence of functional RAG2 and XLF during V(D)J recombination.

$\operatorname{Rag}^{c / c} X L F^{-/-}$pro-B cells accumulate DNA damage foci. Although the absence of normal $V k$-to- $J k$ rearrangement in Rag $2^{c / c} X L F^{-/-} v$-abl pro-B cells could be attributed to defects in DSB repair, it could also arise from decreased RAG cleavage ${ }^{34}$ To test for this possibility, we used automated three-dimensional (3D) microscopy to quantify the presence of DNA damageassociated protein (53BP1) foci at the Igk locus in G1-arrested pro-B cells ${ }^{46,47}$. Upon treatment with ABLki, we found that $33.4 \%(n=36,618$ total nuclei analysed) of WT pro-B cells showed intense 53BP1 foci; the majority contained a single distinct spot, although cells were occasionally found to contain two, and less frequently, three or more foci (Fig. 3a,b and Supplementary Table 1). Dual immuno-staining and DNA fluorescent in situ hybridization (FISH) revealed that the majority of 53BP1 foci co-localized with phosphorylated H2AX $(\gamma \mathrm{H} 2 \mathrm{AX})$ and with the Igk locus, indicating that 53BP1 foci mark the Igk locus undergoing RAG-mediated breaks (Fig. $3 \mathrm{c}$ and Supplementary Figs 3 and 4). To further assess the specificity of 53BP1 foci in marking RAG-initiated DNA damage, we generated Rag2-deficient $\left(\right.$ Rag2 $\left.^{-/-}\right)$pro-B cell lines, that are unable to initiate RAG DNA breaks ${ }^{48}$. In ABLki-treated Rag2 ${ }^{-/}$cell lines, 53BP1 foci were detected in only $12.7 \%(n=18,158)$ of the cells, consistent with the absence of $\mathrm{V}(\mathrm{D}) \mathrm{J}$ rearrangement in these cells $^{48}$, whereas 53BP1 foci were detected in $68 \%(n=14,423)$ of Ku $80^{-1-}$ cells (Fig. 3a,b and Supplementary Table 1). Strikingly, we found that, similarly to Ku80 deficiency, 65.9\% $(n=38,875)$ of Rag $2^{c / c} X L F^{-/-}$pro-B cells harboured 53BP1 foci (Fig. 3a,b and Supplementary Table 1 ), indicating that DNA breaks are readily formed in core RAG2/XLF-deficient cells. Also, similar to Ku80-deficient pro-B cells, $20.4 \%$ of $\mathrm{Rag}^{\mathrm{c} / \mathrm{c}} \mathrm{XLF}^{-/-}$cells contained two 53BP1 foci as compared with 3.6\% $(n=36,618)$, $6 \%(n=46,264)$ and $9.4 \%(n=34,184)$ in WT, Rag2 ${ }^{c / c}$ and $X L F^{-/-}$pro-B cells, respectively (Fig. 3a,b and Supplementary Table 1). Overall, these results indicate that the combined RAG2 and XLF deficiency strongly impairs repair of RAG-mediated DNA breaks, similar to what is seen in the absence of general cNHEJ factors.

End-joining defects in $\operatorname{Rag}^{\boldsymbol{c} / \boldsymbol{c}} \boldsymbol{X} \boldsymbol{L} \boldsymbol{F}^{-/-}$cells. To test unequivocally for $\mathrm{V}(\mathrm{D}) \mathrm{J}$ recombination defects, we transduced $v$-abl pro-B cell lines from each genotype with the pMX-RSSGFP/IRES-hCD4 retroviral recombination substrate (pMX-INV) that allows for GFP expression upon successful chromosomal inversional RAG-mediated recombination and for assessment of the rearrangement status and recombination intermediates by Southern blot analysis 7,34 (Fig. 4a). Flow cytometry and CJ product analyses showed robust levels of pMX-INV 
a
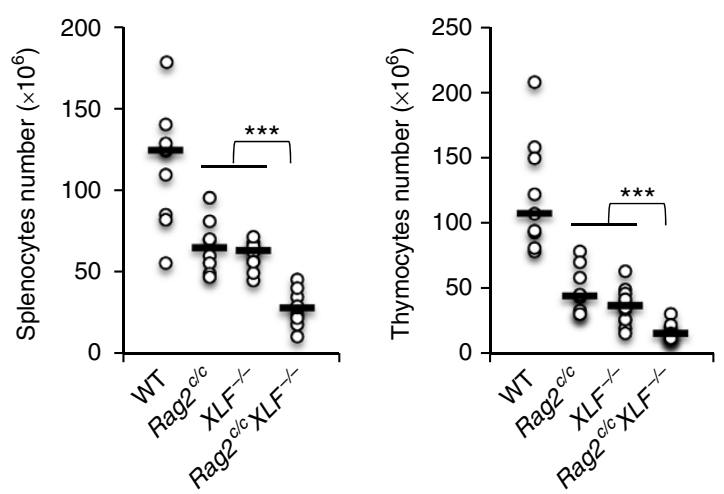

b
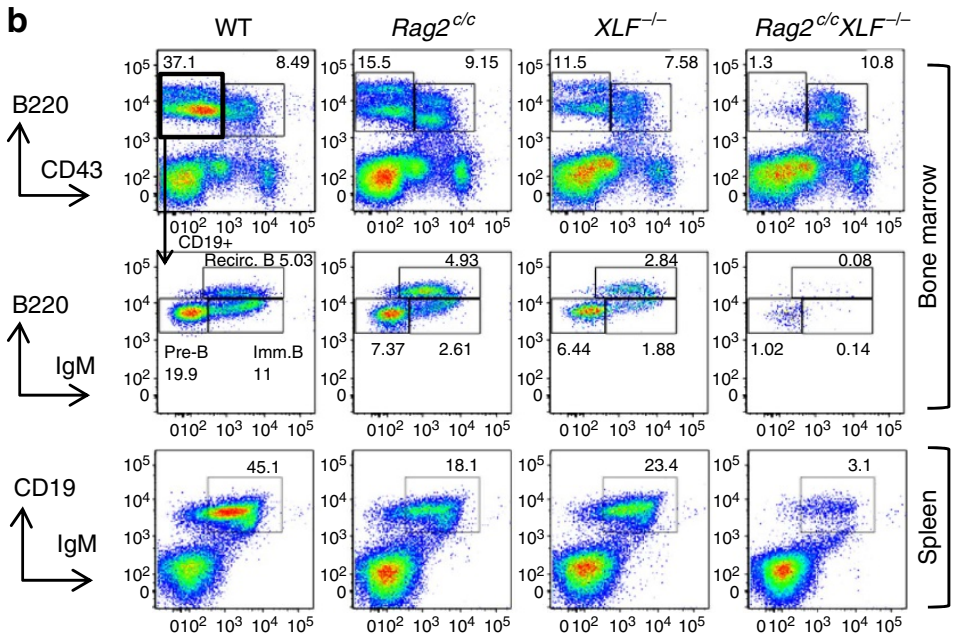

d
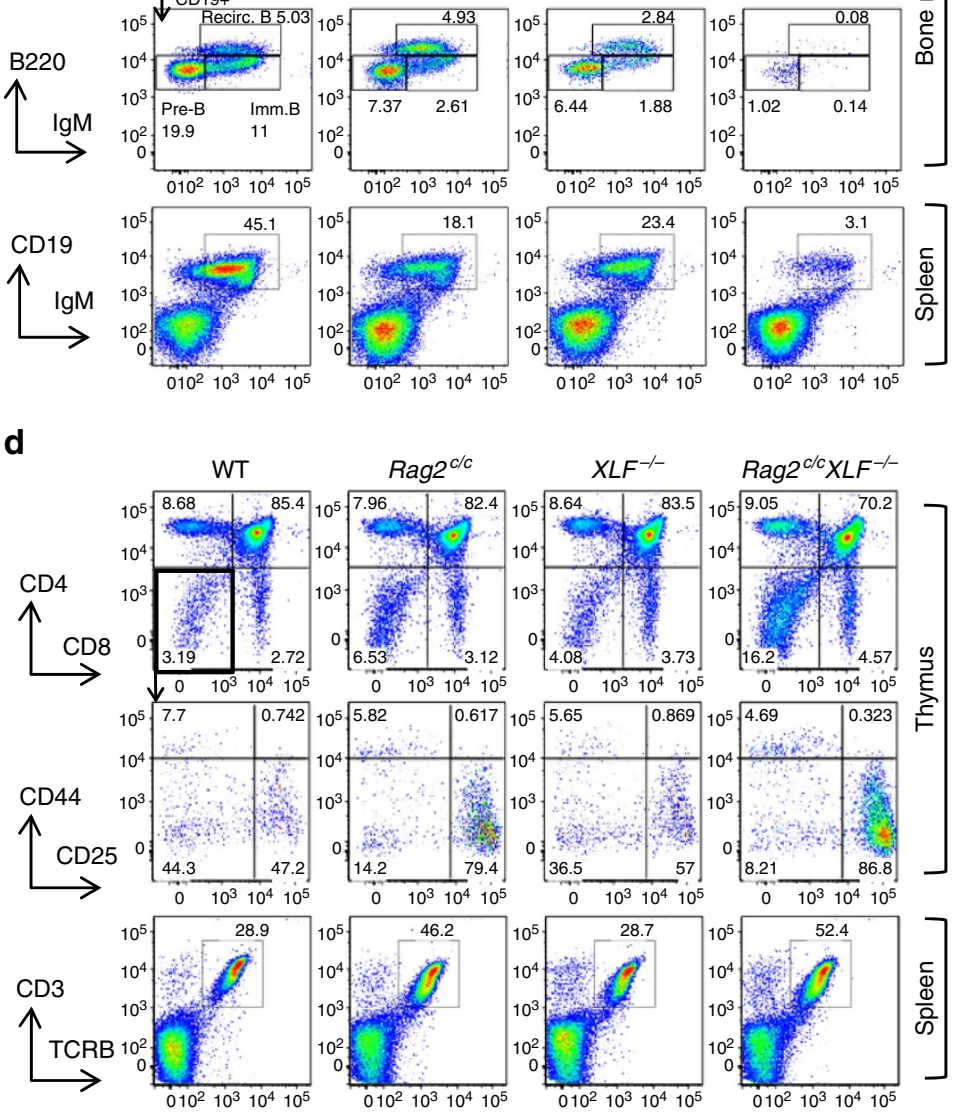

C
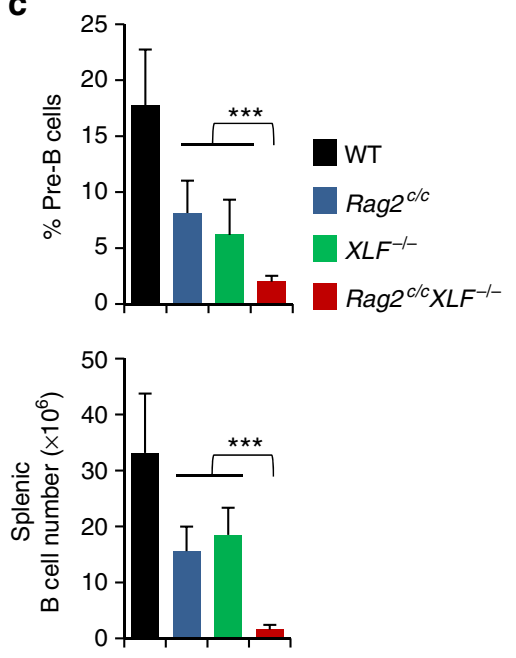

e
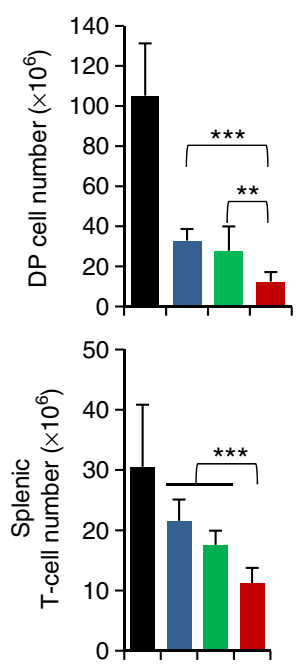

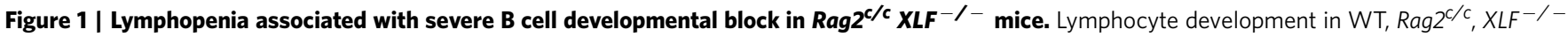
and $\operatorname{Rag} 2^{c / c} X L F^{-/-}$mice. (a) Total splenocyte (left) and thymocyte (right) numbers. Each dot represents one mouse and bars indicate the median. $(\mathbf{b}, \mathbf{c})$ Analysis of B cell development. (b) Representative FACS analysis of bone marrow and spleen using B cell markers. Numbers on plots represent percentages of total cells. (c) Percentage of bone marrow $\mathrm{CD} 43^{-} \mathrm{B} 22 \mathrm{O}^{\mathrm{lo}} \mathrm{CD} 19^{+} \mathrm{IgM}{ }^{-}$pre-B cells (upper) and total number of splenic $\mathrm{CD} 19{ }^{+} \mathrm{IgM}{ }^{+}$ B cells (bottom). (d,e) Analysis of T-cell development. (d) Representative FACS analysis of thymus and spleen using T-cell markers. (e) Total number of thymic DP cells (upper) and splenic $\mathrm{CD} 3^{+} \mathrm{TCR} \beta^{+}$T cells (bottom). Histograms represent means \pm s.d. from at least five mice of each genotype.

${ }^{\star \star} 0.001 \leq P<0.01,{ }^{\star \star \star} P<0.001$.

rearrangement in ABLki-treated WT, $\operatorname{Rag}^{\mathrm{c} / \mathrm{c}}$, and $X L F^{-/-}$cells (Fig. 4b,c and Supplementary Figs 5 and 6a), as expected ${ }^{19,20,34}$. Strikingly, pMX-INV rearrangement was severely impaired in $\mathrm{Rag}^{\mathrm{c} / \mathrm{c}} \mathrm{XLF} \mathrm{F}^{-/}$- cells as compared with WT (30-fold decrease,
$P<0.005)$, Rag2 $^{c / c}(15$-fold decrease, $P<0.005)$ and $X L F^{-/-}$ (15-fold decrease, $P<0.005$ ) cells (Fig. $4 \mathrm{~b}$ and Supplementary Fig. 5b), leading to the absence of rearrangement products (CJ and HJ) (Fig. 4c and Supplementary Fig. 6). In agreement 
a
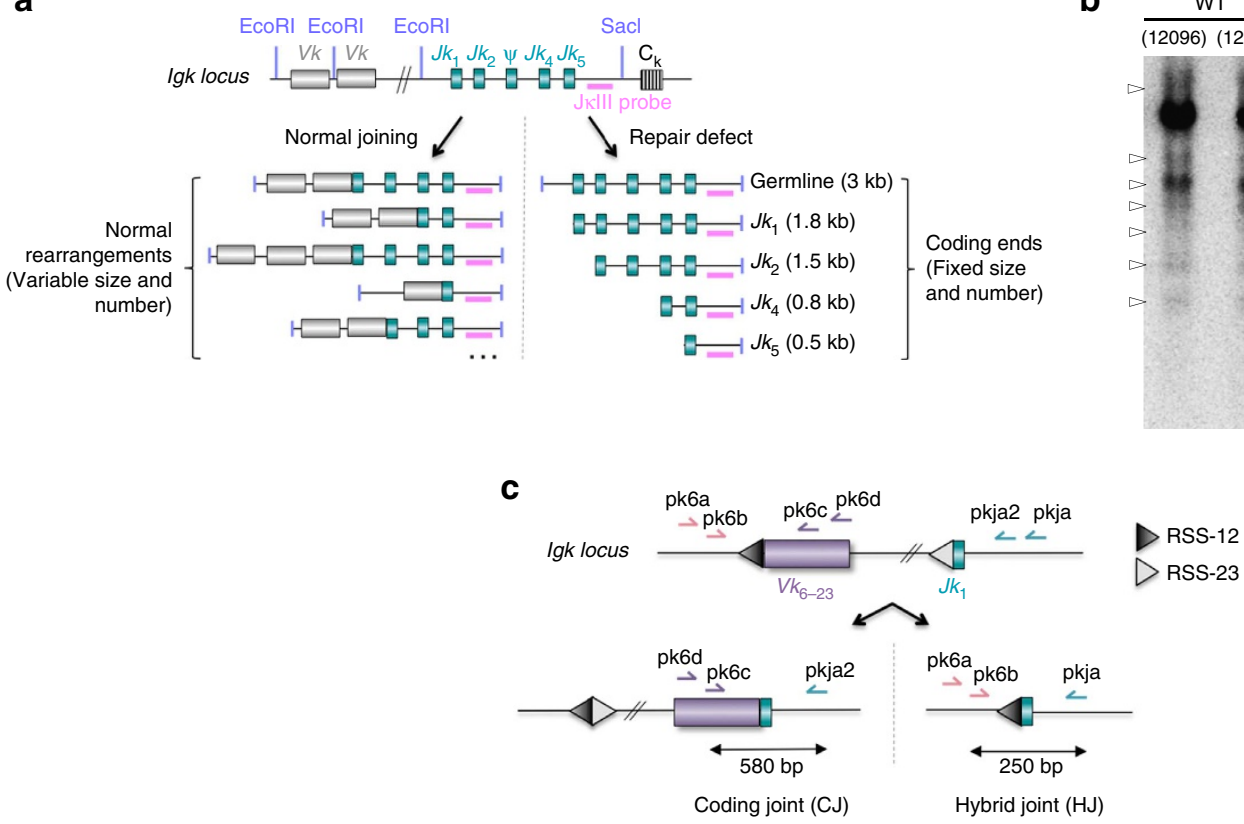

Hybrid joint $(\mathrm{HJ})$ b

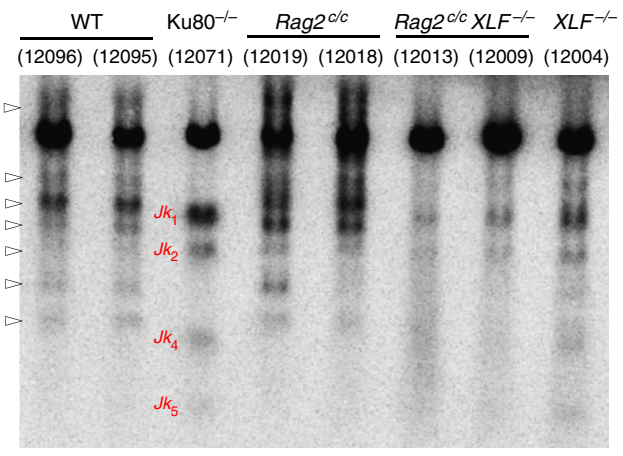

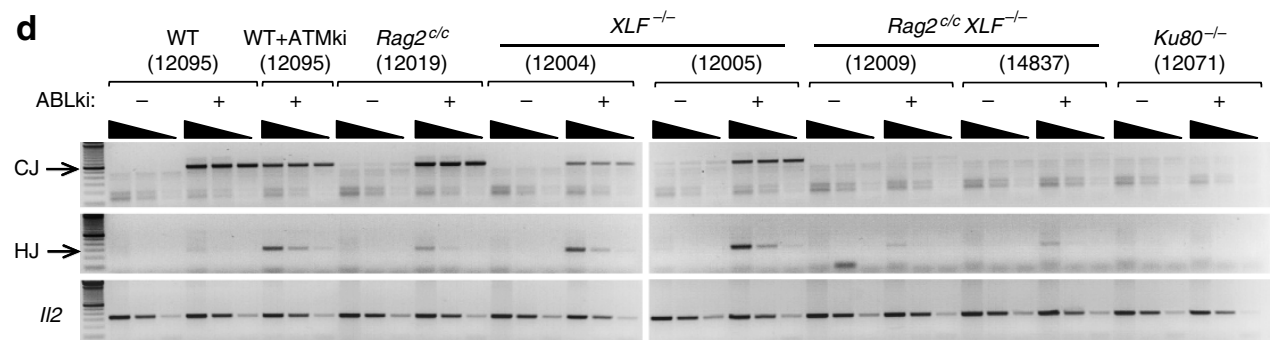

Figure 2 | Impaired rearrangement at the endogenous Igk locus in $\operatorname{Rag2}^{\mathbf{c} / \mathbf{c}} \mathbf{X L F}^{-\boldsymbol{I}}$ - B cells. (a) Schematic representation of the Igk locus. The relative positions of the EcoRI and Sacl restriction sites and the JKIII probe are shown. Schematic representations of Sacl/EcoRI digest fragments for normal $V k$-Jk rearrangements (left) and the $J k 1, J k 2, J k 4$, and $J k 5$ coding ends (CE) (right) are represented. Sacl/EcoRI digest fragments from $V k-J k$ rearrangements are variable in size depending on the $V k$ and $J k$ gene segments used and the relative positions of EcoRI/Sacl sites, whereas the size of $J k 1,2,4$ and 5 coding ends fragments are 1.8, 1.5, 0.8 and $0.5 \mathrm{~kb}$, respectively. (b) Southern blot (using JKIII probe) of EcoRI/Sacl digested DNA from v-abl pro-B cell lines treated for $72 \mathrm{~h}$ with ABLki (see also Supplementary Fig. 2). Arrows indicate normal rearrangements. $J k_{1-5}$ CEs are indicated in red. (c) Schematic representation of the Igk locus with position of primers (arrows) used to assay $\mathrm{CJ}$ and $\mathrm{HJ}$ formation during inversional $\operatorname{lgk} \mathrm{V}_{6-23^{-} J_{1}}$ rearrangement. (d) Semi-quantitative nested PCR analysis of $I g k V_{6-23}-J_{7} \mathrm{CJ}$ and $\mathrm{HJ}$ from indicated $v$-abl abl pro-B cell lines treated for $72 \mathrm{~h}$ with ABLki with or without ATMki. II2 gene PCR was used as a loading control. The data presented are representative of at least two experiments using independent cell lines.

with in vivo results (Supplementary Fig. 1), pMX-INV rearrangement was not dramatically affected in $R a 2^{c / c}$ pro- $\mathrm{B}$ cells treated with the ATMki or in Rag2 $2^{c / c} \mathrm{Atm}^{-/-}$pro-B cells as compared with $\mathrm{Rag}^{\mathrm{c} / \mathrm{c}}$ and $\mathrm{Atm}^{-/}$cells (Fig. 4 and Supplementary Figs 5b and 7). Treatment of WT and $\operatorname{Rag}^{2 / c}$ pro-B cells with ATMki led to the accumulation of HJs and coding ends (CEs) (Fig. 4c and Supplementary Fig. 6), as expected ${ }^{7}$. In contrast, rearrangement was almost completely abolished in $\mathrm{XLF}^{-/-}$cells treated with the ATMki, leading to the accumulation of CEs instead of CJ products (Fig. 4c and Supplementary Fig. 6). These results are in accord with the previously described redundancy between XLF and ATM in joining DNA breaks during V(D)J recombination ${ }^{8,21}$. Moreover, unlike ATMki-treated $\mathrm{XLF}^{-/-}$cells and $\mathrm{Ku}^{-1} \mathrm{O}^{-/-}$cells, very little, if any, CEs accumulated in $R a g 2^{c / c} X F^{-/-}$cells (Fig. 4c and Supplementary Fig. 6). The results are consistent with the weak accumulation of coding ends observed at the $I g k$ locus in Rag2 ${ }^{c / c} X^{2} F^{-1-}$ pro-B cells (Fig. 2 and Supplementary Fig. 2). Lack of $\mathrm{CJ}$ in the absence of $\mathrm{CE}$ accumulation has been previously reported in $\mathrm{H}_{2} \mathrm{AX} \mathrm{X}^{-/-} \mathrm{XLF}^{-/-}$and $53 \mathrm{BP} 1^{-/-} \mathrm{XLF}^{-/-}$cells because $\mathrm{H} 2 \mathrm{AX}$ and 53BP1 are required to protect unrepaired CEs from ATM-mediated degradation ${ }^{8,21,49}$. To test whether RAG2 has a similar function in preventing CE degradation, we performed pMX-INV recombination assays in $\mathrm{Rag}^{\mathrm{c} / \mathrm{C}} \mathrm{XLF}^{-/-}$ cells treated with ATMki. In ABLki-treated Rag2 ${ }^{c / c} X_{L F} F^{-1-}$ cells, ATM kinase inhibition led to the appearance of a visible CE band, indicating that combined RAG2 and XLF deficiency leads to accumulation of unrepaired coding ends that are exposed to ATM-dependent degradation (Fig. 4c and Supplementary Fig. 6). In support to these results, we also readily detected $I g k J_{1-4} \mathrm{CEs}$ in $\mathrm{Rag}^{\mathrm{c} / \mathrm{c}} \mathrm{XLF}^{-1-}$ cells treated with ABLki and ATMki (Supplementary Fig. 2b). Interestingly, we also noticed that ABLki/ATMki treated $\mathrm{Ku}^{-1-}$ cells showed stronger levels of unrepaired CEs as compared with ABLki-treated $\mathrm{Ku} 80^{-/-}$cells, indicating that a significant fraction of unrepaired CEs are subjected to ATM-dependent end degradation in Ku80-deficient cells (Fig. 4c).

We also tested for $\mathrm{V}(\mathrm{D}) \mathrm{J}$ recombination defects with a substrate that rearranged by deletion (pMX-DEL-CJ), resulting in the formation of a $\mathrm{CJ}$ that remained within the chromosomal context (Fig. 5a and Supplementary Fig. 8a). PCR and Southern blot analysis confirmed severely defective end-joining 
a

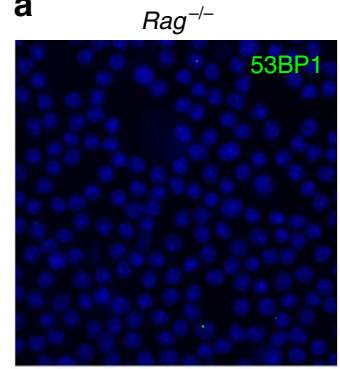

$\operatorname{Rag}^{c / c} X^{\prime-1}$

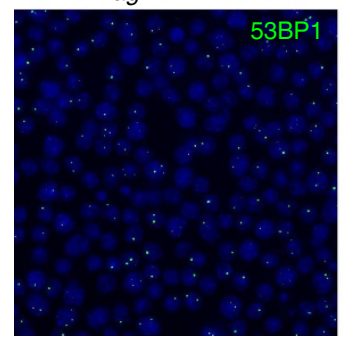

WT

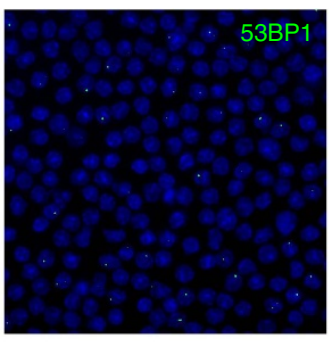

$K u 80^{-1-}$

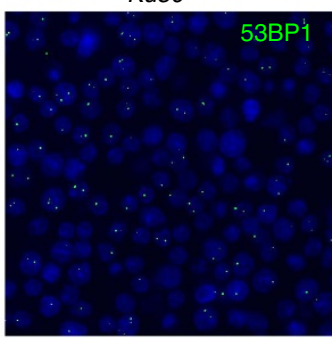

b

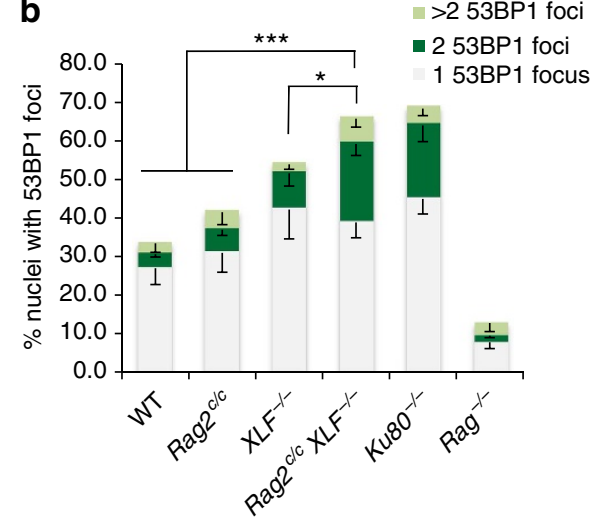

C

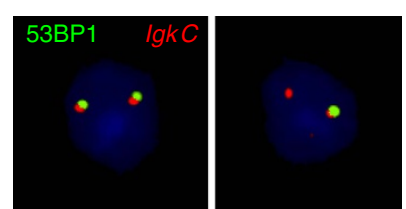

Figure 3 | Accumulation of RAG-induced 53BP1 foci in $\mathbf{R a g 2}^{\mathbf{C} / \mathbf{c}} \mathbf{X L F}^{-/-}$B cells. (a) Representative 3D projections of 53BP1 immuno-staining conducted on ABLki-treated v-abl pro-B cells. (b) Percentage of v-abl pro-B cells harbouring 1, 2 or $>253 B P 1$ foci $65 \mathrm{~h}$ post-ABLki treatment. Histograms represent means \pm s.d. from four independent experiments with two independent cell lines for each genotype (see Supplementary Table 1 for details). ${ }^{\star} 0.01 \leq P<0.05,{ }^{\star \star \star} P<0.001$. (c) Fluorescent light microscopy images of immuno-3D FISH analysis conducted on ABLki-treated Rag2 ${ }^{c / c} X L F{ }^{-/}-$ $v$-abl pro-B cells. Nuclei were stained with anti-53BP1 antibody (green) and subsequently hybridized with the centromeric lgk BAC probe (Igk C, red). Images show 2 nuclei with coincident 53BP1/lgk signals (see Supplementary Fig. 4 for details).

in ABLki-treated $\mathrm{Rag}^{\mathrm{c} / \mathrm{c}} \mathrm{XLF} \mathrm{F}^{-/-}$pro-B cell lines and a marked increase in un-joined CEs upon treatment with ATMki (Fig. 5b,c and Supplementary Fig. 8b). Notably, PCR analysis of CJ products revealed that ATM inhibition slightly, but consistently, reduced CJ formation in $\mathrm{Rag}^{c / c} \mathrm{XLF}^{-/-}$cells, highlighting a RAG-independent function of ATM in XLF-deficient cells (Fig. 5c and Supplementary Fig. 8b). These results were also supported by the reduced GFP expression in ABLki/ATMki

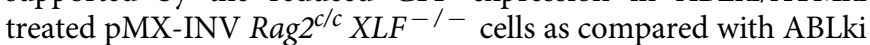
treatment only (Fig. $4 \mathrm{~b}$ and Supplementary Fig. 5b). Sequences of rare CIs derived from $\mathrm{Rag}^{c / c} \mathrm{XLF}^{-/-}$cells harboured increased deletions and microhomology usage as compared with single mutant and WT cells (Fig. 5d, Supplementary Fig. 9 and Supplementary Table 2). These events were reminiscent of rare joints seen in cNHEJ-deficient cells, indicating aberrant alternative NHEJ in core RAG2/XLF-deficient cells. Together, these results indicate that the RAG complex and XLF participate in repairing RAG-mediated DNA breaks and in protecting them from aberrant end-joining and ATM-mediated degradation.

Genomic instability in $\operatorname{Rag}^{c / c} X L F^{-/-} p 53^{-/-}$B cells. We next hypothesized that unrepaired DNA breaks in G1 arrested $\mathrm{Rag}^{\mathrm{c} / \mathrm{c}} \mathrm{XLF}^{-/-}$pro-B cells might lead to chromosomal instability upon re-entry into the cell cycle. To test our hypothesis, we performed DNA-FISH on chromosome spreads prepared from untreated cycling cells and G1-arrested cells released back into cell cycle by removal of ABLki. Using probes centromeric $(\operatorname{Igk} V)$ and telomeric $(\operatorname{Igk} C)$ to the $\operatorname{Igk}$ locus together with specific paint for chromosome 6, we quantified the frequency of Igk chromosome breaks and translocations (Fig. 6a-c, Supplementary Table 3). Since DNA breaks induce strong p53dependent G1/S checkpoint and apoptotic signalling, we generated additional $v$-abl pro-B cell lines derived from $p 53^{-/-}$, $\mathrm{Rag}^{c / c} p 53^{-/-}, \mathrm{XLF}^{-1-} \mathrm{p} 53^{-/-}$and $\mathrm{Rag} 2^{c / c} \mathrm{XLF} \mathrm{F}^{-/-} \mathrm{p} 53^{-/-}$ mice. Interestingly, metaphases prepared from released $\mathrm{Rag}^{\mathrm{c} / \mathrm{c}} X L F^{-/-} p 53^{-/-}$pro-B cells harboured a statistically significant increase in genomic instability, most notably translocations $(17.7 \%, n=724)$, as compared with $p 53^{-/-}(6 \%$, $n=745), \operatorname{Rag}^{c / c} p 53^{-/-}(8 \%, n=250)$ and $X L F^{-/-} p 53^{-/-}$ $(5.7 \%, n=403)$ pro-B cells (Fig. $6 \mathrm{c}$ and Supplementary Table 3 ). To determine whether chromosome breaks and translocations were detectable in primary $\mathrm{B}$ cell progenitors, we cultured bone marrow $\mathrm{CD}_{19}{ }^{+} \mathrm{IgM}^{-}$cells and examined metaphases using probes centromeric $(\operatorname{Igh} C)$ and telomeric $(\operatorname{Igh} V)$ to the Igh locus plus specific paint for chromosome 12 (Fig. 6d-f and Supplementary Table 4). We found very low levels of Igh breaks and translocations in p53 proficient pro-B cells (Supplementary Table 4). In contrast, we detected a significant increase in these lesions in $\mathrm{Rag}^{c / c} X L F^{-/-} p 53^{-/-}$pro-B cells $(10.3 \%, n=943)$ when compared with $p 53^{-/-}(1.7 \%, n=421), R_{a g} 2^{c / c} p 53^{-/-}$ (3.5\%, $n=883)$ and $X L F^{-/-} p 53^{-/-}(4.2 \%, n=910)$ pro-B cells (Fig. $6 \mathrm{f}$ and Supplementary Table 4). We conclude that Rag ${ }^{c / c} X L F^{-1-}$ primary pro-B cells, like $v$-abl pro-B cell lines, harbour high levels of genomic aberrations at the rearranging Ig loci that persist in the absence of p53-dependent cell cycle/ apoptotic checkpoint. These results reveal unique redundant functions between RAG2 and XLF in suppressing genomic instability during antigen receptor gene assembly.

$\operatorname{Rag}^{c / c} X L F^{-/-} p 53^{-/-}$mice develop pro-B cell lymphomas. cNHEJ/p53-deficient mice irremediably develop pro-B cell lymphomas associated with aberrant $\mathrm{V}(\mathrm{D}) \mathrm{J}$ recombination driven clonal translocations and gene amplifications ${ }^{50,51}$. In contrast, the majority of $X L F^{-/-} p 53^{-/-}$mice succumb to T-cell lymphomas lacking recurrent translocations ${ }^{20}$. Thus, we wondered whether combined RAG2/XLF/p53-triple-deficiency might affect tumour outcomes in these mice. $\operatorname{Rag}^{c / c} X L F^{-/-} p 53^{-/-}$animals survived an average of 11.5 weeks, indistinguishable from $\operatorname{Rag}^{c / c} p 53^{-/-}$mice (mean survival $=12.4$ weeks), but significantly less than $X L F^{-/-} p 53^{-/-}$animals (15 weeks) (Supplementary Fig. 10). Seventeen of the twenty-two Rag2 $^{c / c} X L F^{-/-} p 53^{-/-}$mice died of T-cell lymphomas harbouring clonal chromosomal translocations involving the Igh and $T c r \alpha / \delta$ loci, most likely resulting from $\mathrm{Rag}^{\mathrm{c} / \mathrm{c}} \mathrm{p53^{- \rho _{- } }}$ 
deficiency $^{30}$ (Fig. 7a, Supplementary Fig. 10 and Supplementary Table 5). Strikingly, 5 of the $22 \mathrm{Rag}^{\mathrm{c} / \mathrm{c}} X L F^{-/-} p 53^{-/-}$ mice succumbed to pro-B cell lymphomas (Fig. $7 \mathrm{a}$ and Supplementary Table 6), consistent with the observation that Rag2 $^{c / c} X L F^{-1-} p 53^{-1-}$ pro-B cells harbour high levels of genomic instability (Fig. 6f). Interestingly, spectral karyotyping and DNA-FISH analysis using $I g h$ and $c-m y c$ specific probes revealed recurrent translocations between chromosomes 12 and 15 associated with co-amplifications of the Igh locus and the $c$-myc oncogene in all five B-cell lymphomas (Fig. 7b,c, and Supplementary Table 6), similar to what has been reported in cNHEJ/p53-deficient mice ${ }^{51}$. To further analyse $\mathrm{Rag}^{\mathrm{c} / \mathrm{c}} \mathrm{XLF}^{-/-} \mathrm{p53^{-/ }}$ pro-B lymphomas, we whole-genome sequenced three tumours. In all three pro-B cell lymphomas analysed, copy number variation analysis confirmed amplification of the Igh locus and $c-m y c$ (Fig. 7d and Supplementary Fig. 11) and

a
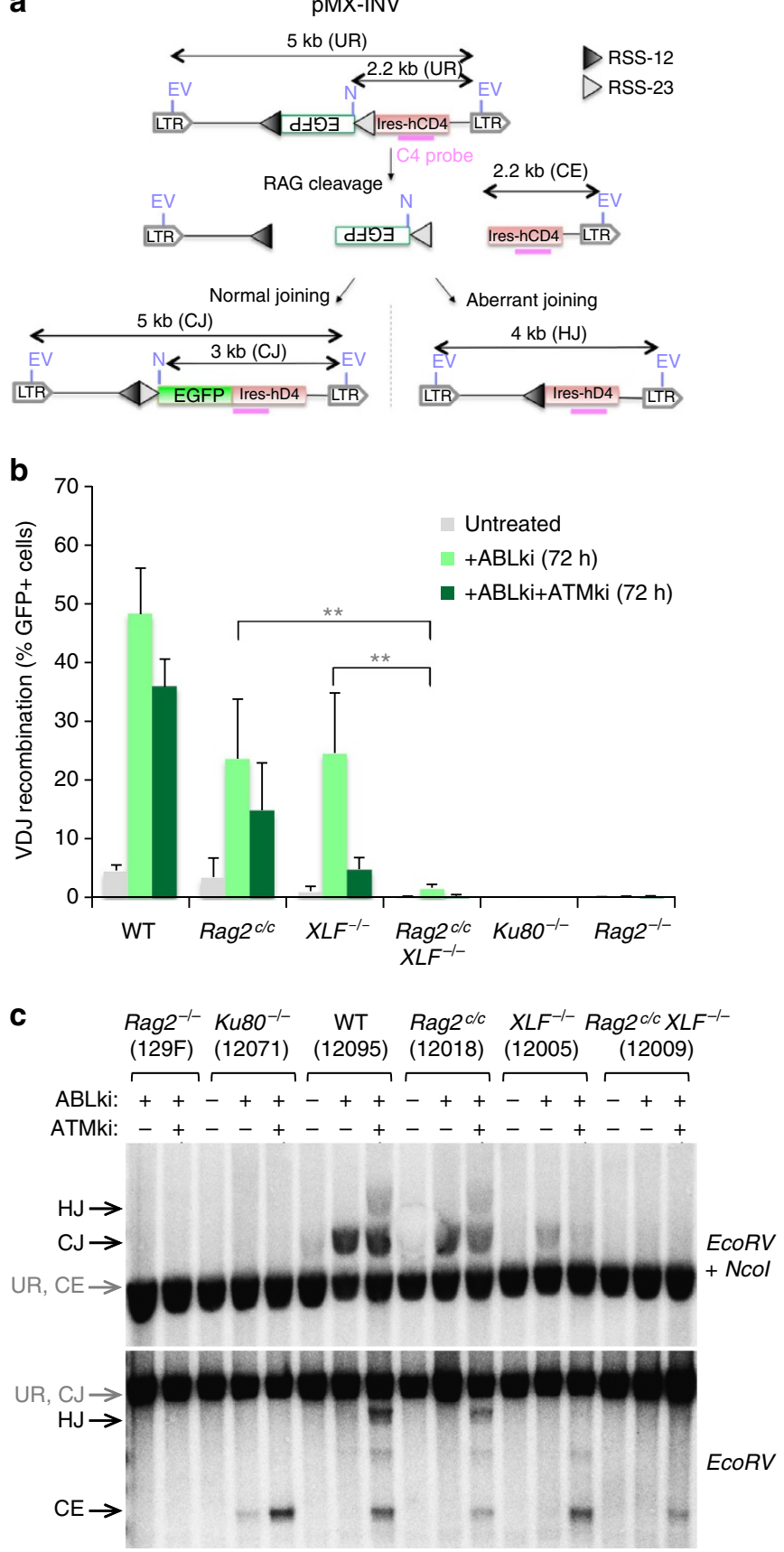

structural variant calling revealed multiple translocations (Fig. 7d, Supplementary Fig. 11 and Supplementary Data 1) among which the most frequent rearrangement fused the Igh locus to a sequence downstream of the $c-m y c$ gene encoding for $p v t 1$, a lncRNA (Supplementary Fig. 11b and Supplementary Data 1). Interestingly, most translocation junctions contained short sequence homology indicating possible involvement of alternative NHEJ pathway (Supplementary Fig. 11b and Supplementary Data 1 ), which is mostly operative in the absence of functional repair by cNHEJ and/or destabilization of the RAG-PCC $3,29,31,32,51$. Together, these results indicate that, in the context of XLF deficiency, the RAG complex (more specifically the RAG2 C-terminus) behaves as a genome caretaker that maintains the integrity of the genome by promoting accurate repair of RAG-mediated DNA breaks and suppressing chromosomal rearrangements.

\section{Discussion}

The repair of RAG-induced DSB is known to be fully dependent on core cNHEJ factors (Ku70/80, XRCC4 and Ligase IV) and DNA-PKcs/Artemis in the context of CJ formation ${ }^{3-5}$. XLF is a cNHEJ factor but is not required for V(D)J recombination ${ }^{19,20}$. Here, we find that the RAG complex and XLF functionally overlap in the repair of DNA breaks during antigen receptor assembly. Our data provide multiple lines of evidence supporting the conclusion that, in the absence of XLF, the RAG complex plays a direct role in assisting repair of chromosomal RAG DSBs. Contrary to single deficiency due to loss of the C-terminal region of RAG2 (core RAG2) or XLF that do not harbour major defects in $\mathrm{V}(\mathrm{D}) \mathrm{J}$ recombination, we find that combined core RAG2 and XLF deficiency leads to a block in lymphocyte development at the progenitor stage when $\mathrm{V}(\mathrm{D}) \mathrm{J}$ recombination occurs, very reminiscent of the severe combined immunodeficiency phenotype observed in cNHEJ-deficient mice. Utilizing core RAG2/XLFdeficient $v$-abl pro-B cells, we were able to show that (i) these cells, when arrested in G1 to induce RAG expression, accumulate RAG-dependent 53BP1/ $\gamma \mathrm{H} 2 \mathrm{AX}$ DNA repair foci to similar levels observed in Ku80-deficient cells and display severe impairment in joining RAG DSBs, (ii) rare CJs detected in these cells harbour deletions and microhomologies reminiscent of rare joints seen in core cNHEJ-deficient cells and (iii) in the context of p53 deficiency, these cells and primary pro-B cells accumulate genomic instability in the form of chromosomal breaks and

Figure 4 | Defective inversional V(D)J recombination in Rag2 $^{\mathbf{c} / \mathbf{c}} \mathbf{X L F}^{-/-}$ B cells. (a) Schematic representation of $p M X-I N V$ recombination substrate. The 12-recombination signal sequence (RSS-12; black triangle), GFP cDNA, 23-recombination signal sequence (RSS-23; grey triangle), IRES-human CD4 cDNA (IRES-hCD4), LTRs, EcoRV (EV) sites, Ncol (N) site, C4 probe (pink bar), and the expected sizes for the un-rearranged substrate (UR), coding end intermediates (CE), coding joints $(\mathrm{CJ})$ and hybrid joints $(\mathrm{HJ})$ are indicated. (b) $v$-abl pro-B cell lines treated for $72 \mathrm{~h}$ with ABLki with or without ATM kinase inhibitor (ATMki) were assayed for $\mathrm{pMX-INV}$ rearrangement by flow cytometry, with the percentage of GFP expressing cells indicated. Histograms represent the means \pm s.d. of 2 WT (12095 and 12096), $2 \operatorname{Rag}^{c / c}$ (12018 and 12019), 4 XLF $^{-/-}(12004,12005,16218$ and

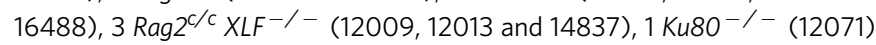
and 3 Rag $2^{-/-}(129,16605$ and 16610) independent cell lines.

Experiments were repeated three times for ABLki-treated cells and performed once for ABLki/ATMki-treated cell lines. ${ }^{\star \star} P<0.005$. (c) The indicated $v$-abl pro-B cell lines containing the $\mathrm{pMX}$-INV substrate were treated for $72 \mathrm{~h}$ with ABLki with or without ATMki and assayed by Southern blotting; EcoRV/Ncol digest-C4 probe (top panel) and EcoRV digest-C4 probe (bottom panel). The data presented are representative of at least two experiments using independent cell lines (see also Supplementary Fig. 7). 
a

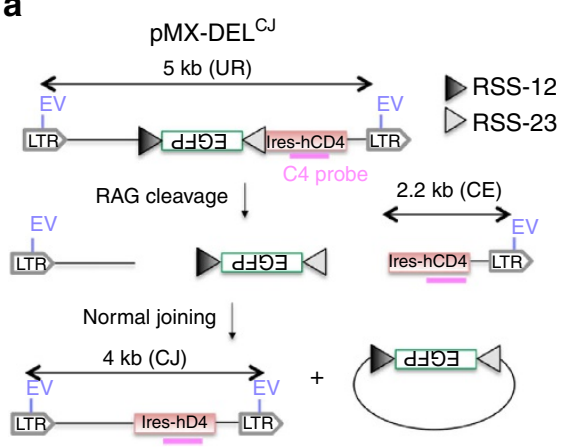

b

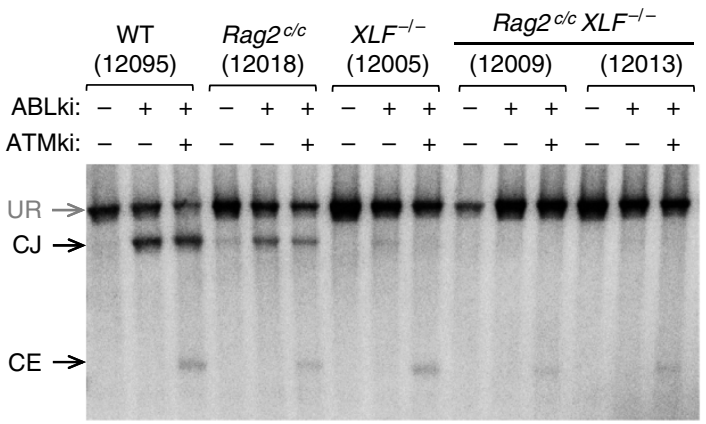

C

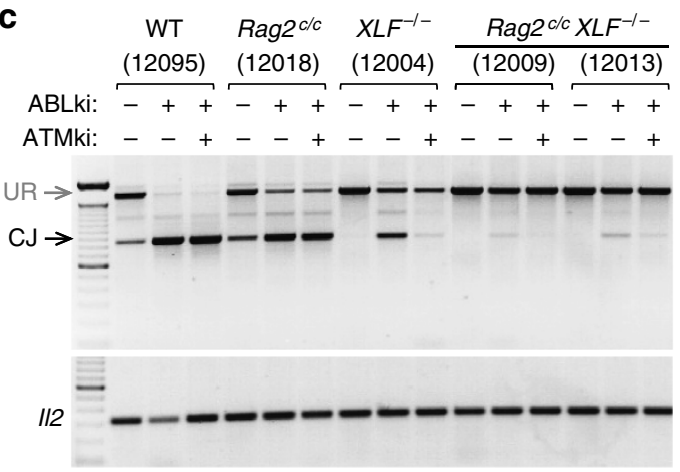

d

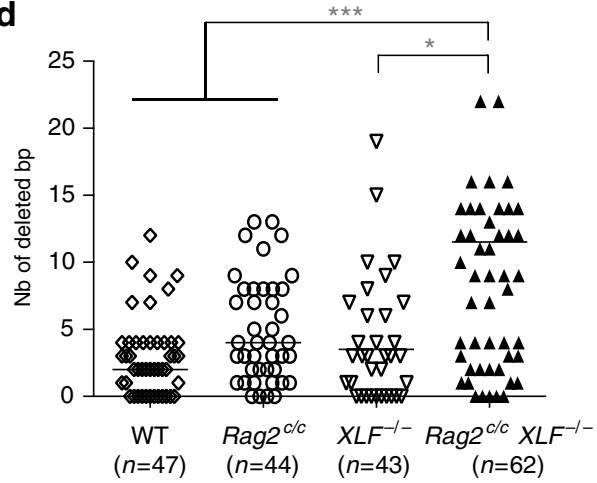

Figure 5 | Defective deletional V(D)J recombination and abnormal CJ formation in $\mathbf{R a g 2}^{\mathbf{C} / \mathbf{c}} \mathbf{X L F}^{-/-} \mathbf{B}$ cells. (a) Schematic representation of pMX-DEL ${ }^{\mathrm{CJ}}$ recombination substrate with components, intermediates and products as defined for pMX-INV in Fig. $4 \mathrm{a}$. (b) $v$-abl pro-B cell lines containing pMX-DEL ${ }^{\mathrm{CJ}}$ were treated for $72 \mathrm{~h}$ with ABLki with or without ATMki and assayed by Southern blotting; EcoRV digest-C4 probe. Experiments were repeated at least two times. (c) PCR analysis of $\mathrm{pMX}-\mathrm{DEL}{ }^{\mathrm{CJ}} \mathrm{CJ}$ from indicated $\mathrm{v}$-abl abl pro-B cell lines treated for $72 \mathrm{~h}$ with ABLki with or without ATMki. 112 gene PCR was used as a loading control. Experiments were repeated at least two times and PCR specificity was confirmed by Southern blotting (Supplementary Fig. 8). (d) Sanger sequencing of PCR amplified CJs from v-abl pro-B cells (see also Supplementary Table 2). Number of base-pair deletions is indicated on the $y$-axis. The horizontal bar represents the median. The total number of sequenced CJs $(n)$ is indicated. Outliers ( $>25 \mathrm{bp}$ deletion) are not shown but are included in calculation of the median. ${ }^{\star} 0.01 \leq P<0.05,{ }^{\star \star \star} P<0.001$.

translocations. Lastly, we found that $\operatorname{Rag}^{c / c} X L F^{-/-} p 53^{-/-}$ mice develop pro-B cell lymphomas carrying chromosomal translocations and gene amplification involving the Igh and c-myc loci, similarly to core $\mathrm{cNHEJ} / \mathrm{p} 53$ double-deficient mice. These results are consistent with a severe end-joining defect in core RAG2/XLF-deficient cells and demonstrate that core RAG2 $\mathrm{B}$ cells require XLF and reciprocally XLF-deficient $\mathrm{B}$ cells require RAG to achieve DNA end repair during $V(D) J$ recombination.

A major challenge will be to elucidate the nature of the overlapping functions of XLF and the RAG complex in the repair of RAG-mediated DNA breaks and whether they act in the same general function (for example, end-stabilization/tethering) or in unique pathways (for example, end-stabilization/tethering versus cNHEJ factor recruitment, joining kinetics, end-protection/ resection) that are functionally compensatory. Based on our results and previous work, we favour a two-tier synapse model in which both the RAG-PCC and XLF ensure stabilization of DNA ends following RAG1/2 cleavage. ATM and/or ATM-dependent DDR factors would contribute to the RAG-PCC in accord with their role in RAG-DSB stabilization and with their observed functional redundancy with XLF during V(D)J recombination ${ }^{6,8}$ (Supplementary Fig. 12-see below).

Consistent with this model, core-RAG2 is known to destabilize the RAG-PCC in vitro and to increase the rate of aberrant recombination product formation in vivo including $\mathrm{HJs}$ and inter-chromosomal translocations involving $\mathrm{V}(\mathrm{D}) \mathrm{J}$ loci i $^{2-31,36,37,39}$. XLF forms, with XRCC4, long heterofilaments in vitro and in vivo potentially capable of maintaining the broken ends together while they are processed for ligation ${ }^{14-18}$. Disrupting the interaction between XLF and XRCC4 leads to impaired coding (but not signal) joint formation ${ }^{52}$. Since the RAG proteins bind much more avidly to signal-end pairs than coding-end pairs in vitro ${ }^{2}$, this might reflect end-stabilization activities of the XLF-XRCC4 filaments that are more strongly compensated for by signal-end tethering provided by the RAG PCC. Additionally, during inversional V-to-J recombination at the Igk locus, similar to Rag2 ${ }^{c / c}$ or $\mathrm{Atm}^{-/-}$ pro-B cells ${ }^{7,30}, X L F^{-/-}$pro-B cells show increased $\mathrm{HJ}$ formation, revealing a role for XLF in the stabilization of RAGinduced chromosomal DSBs. Notably, Southern blotting analysis revealed that, in addition to rearranged products, low levels of unrepaired coding ends are detectable at the Igk locus in $X L F^{-/-}$ pro- $B$ cells. The presence of these unrepaired coding ends is consistent with a role for XLF in stabilizing RAG-DSBs or with a role in general DSB joining ${ }^{18,53,54}$. Therefore, in addition to DNA end destabilization, a mild decrease in joining kinetics and/or efficiency caused by XLF deficiency alone ${ }^{18,21,53,54}$ might also contribute to the observed end-joining defect in $\mathrm{Rag}^{2 / C} \mathrm{XLF}^{-/-}$cells.

Absence of a double safe-lock provided by RAG and ATM-DDR on one side and XLF/XRCC4 on the other side might ultimately cause the collapse of PCCs (Supplementary Fig. 12), leading to release/vulnerability of DNA ends and an absence of cis-rearrangement products. This is consistent with the observation of severely impaired joining of RAG-generated DSBs in cells that are doubly deficient for XLF and either ATM, 53BP1 or H2AX (ref. 8) as well as in core RAG2/XLF-deficient cells. 
a

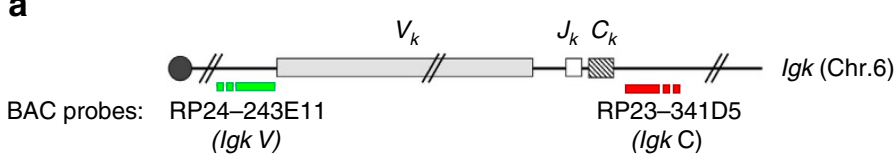

b

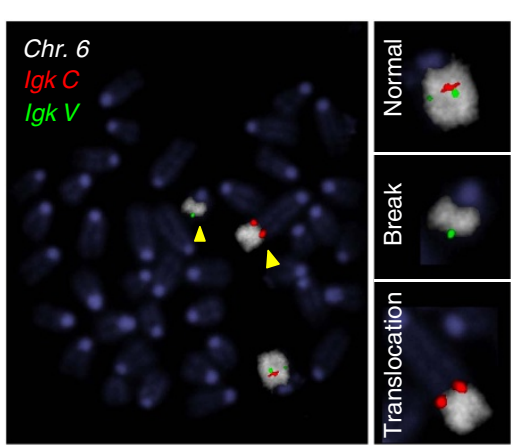

C
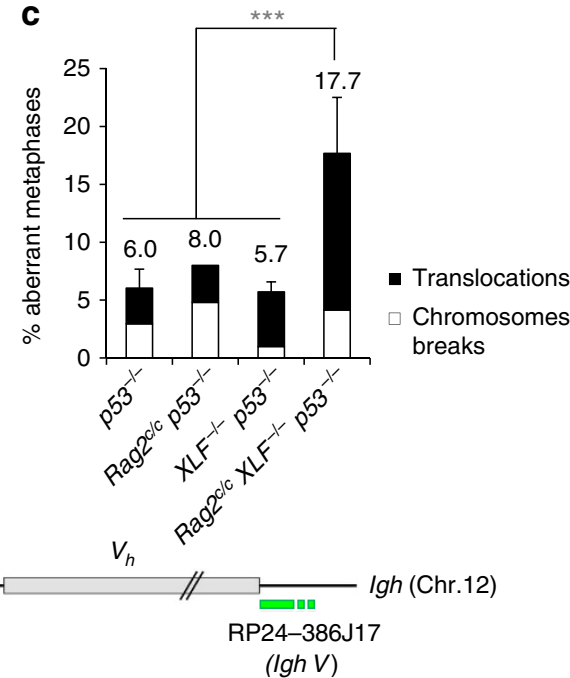

e

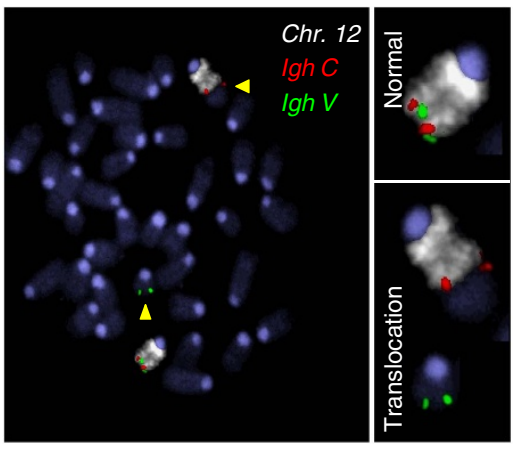

f

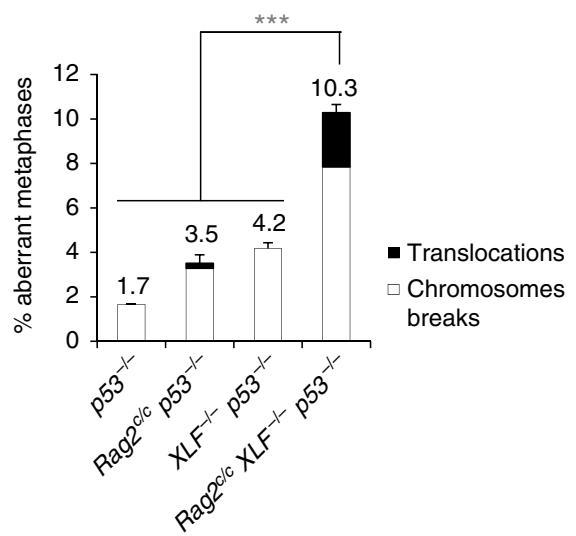

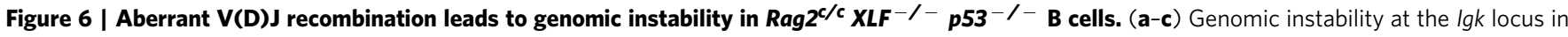
$v$ - $a b l$ pro-B cell lines. (a) Schematic representation of the Igk locus, with positions of the BACs used for generation of DNA FISH probes indicated. (b) Representative metaphase from $\operatorname{Rag}^{c / c} X L F^{-/-} p 53^{-/-} v$-abl pro-B cell lines using the Igk C BAC probe (red) combined with Igk $V$ BAC probe (green) and chromosome 6 paint (white). Yellow arrowheads point to broken or translocated chromosome 6. (c) Percentage of aberrant metaphases from $v$ - $a b /$ pro-B cell lines of the indicated genotype harbouring chromosomes breaks (white) or translocations (black) involving the lgk locus. Histograms represent means + s.e.m. of two to three independent cell lines (see also Supplementary Table 3). ${ }^{\star \star \star} P<0.001$. (d-f) Genomic instability at the Igh locus in primary pro-B cells. (d) Schematic representation of the Igh locus, with positions of the BACs used for generation of DNA FISH probes indicated.

(e) Representative metaphase from $\operatorname{Rag}^{c / c} X \mathrm{XF}^{-/-} p 53^{-/-}$pro-B cells using the Igh C BAC probe (red) combined with Igh $V$ BAC probe (green) and chromosome 12 paint (white). Yellow arrowheads point to broken or translocated chromosome 12. (f) Percentage of aberrant metaphases from pro-B cells of the indicated genotype harbouring chromosomes breaks (white) or translocations (black) involving the lgh locus. Histograms represent means \pm s.e.m. of at least three independent experiments (See also Supplementary Table 4). ${ }^{\star \star \star} P<0.001$.

Notably, while un-joined DNA ends remain intact in G1-arrested $\mathrm{XLF} / \mathrm{ATM}$ double-deficient pro-B cells, they are highly resected in $\mathrm{XLF} / \mathrm{H} 2 \mathrm{AX}$ or XLF/53BP1 double-deficient cells because of the DNA end resection activity of $\mathrm{CtIP}^{49}$, and possibly KAP-1 (ref. 55). During V(D)J recombination, ATM has a dual impact on DNA end fate, both protecting these ends from release/ resection possibly via their stabilization within PCCs and promoting their resection by activating CtIP. Therefore, RAG-cleaved DNA ends might be released/exposed in all cases where the two locks (ATM-DDR/RAG PCC and XLF) are missing but only subjected to resection in the presence of a functional ATM kinase. Correspondingly, inhibition of the ATM kinase activity in XLF/H2AX or XLF/53BP1 double-deficient pro- $\mathrm{B}$ cells restores accumulation of intact unrepaired DNA ends ${ }^{8,21}$. Similarly, in $R a g 2^{c / c} X L F^{-/-}$pro-B cells, intact unrepaired DNA ends were rescued by treatment of cells with an ATM kinase inhibitor.

It is tantalizing to speculate that the RAG proteins and the ATM-DDR participate in the same pathway that is functionally redundant with XLF. This is supported by our findings showing that (1) $\mathrm{Rag}^{\mathrm{c} / \mathrm{c}} \mathrm{Atm} \mathrm{tm}^{-/-}$mice display relatively normal $\mathrm{B}$ and T lymphocyte development, (2) $\mathrm{V}(\mathrm{D}) \mathrm{J}$ recombination is not abolished in $\mathrm{Rag}^{\mathrm{c} / \mathrm{c}} \mathrm{Atm}{ }^{-/}-v$-abl pro-B cells, (3) $\mathrm{Rag}^{\mathrm{c} / \mathrm{c}} \mathrm{Atm}^{-1-}$ developing $\mathrm{B}$ and $\mathrm{T}$ cells and $v$-abl pro-B cells harbour similar 
a

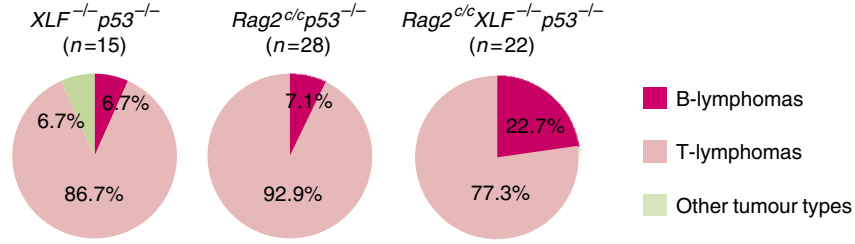

b
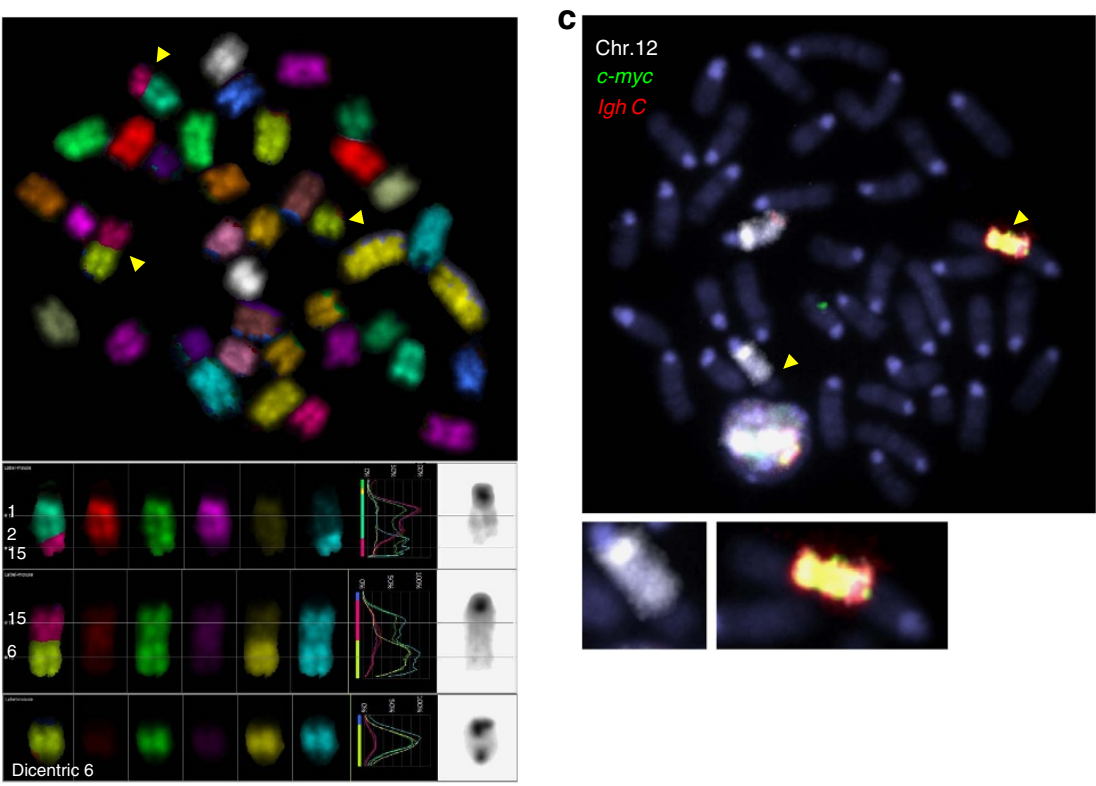

d
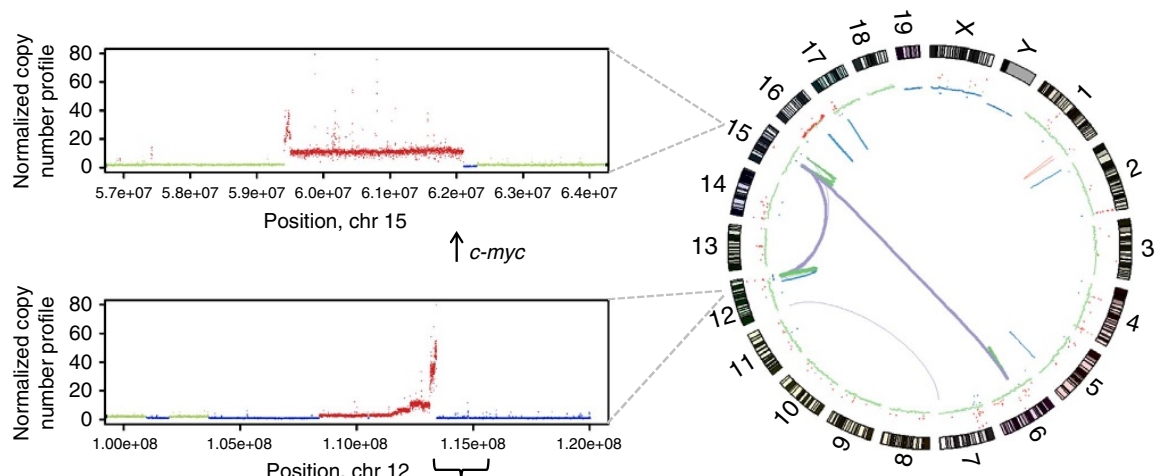

Figure $7 \mid \mathbf{R a g 2}^{\mathrm{c} / \mathrm{c}} \mathbf{X L F}^{-/-} \mathbf{p 5 3} \mathbf{3}^{-/-}$mice develop pro-B cell lymphomas harbouring $\mathbf{I g h / c - m y c}$ translocations associated with gene amplification. (a) Tumour spectrum analysis of $X L F^{-/-} p 53^{-/-}(n=15), \operatorname{Rag}^{c / c} p 53^{-/-}(n=28)$ and Rag2 $2^{c / c} X L F^{-/-} p 53^{-/-}$mice $(n=22)$. (b) Representative images of spectral karyotyping analysis of $1 \operatorname{Rag}^{\mathrm{c} / \mathrm{C}} \mathrm{XLF}^{-/-} \mathrm{p53}-/-\mathrm{B}$ lymphoma (\#14189LN). Five B lymphomas were analysed (see also Supplementary

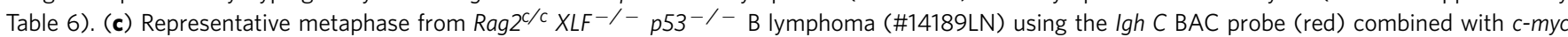
$B A C$ probe (green) and chromosome 12 paint (white). Experiments were repeated on five different samples. (d) Circos plot showing chromosomal rearrangements of B lymphoma \#14189LN identified by WGS. Chromosomes are arranged circularly end-to-end with each chromosome's cytobands marked in the outer ring. The inner ring displays copy number data inferred from WGS with blue dots indicating losses, red dots indicating gains and green dots indicating normal copy numbers. Within circles, purple, orange, green and blue lines represent inter-chromosomal rearrangements, duplications, inversions and deletions, respectively. The thickness of the link is proportional to the number of read pairs supporting the structural variant. The left panels depict copy number variations in specific regions of chromosome 12 (bottom) and 15 (upper). A total of 3 Rag $2^{c / C} X^{C} F^{-/-} p 53^{-/-} B$ lymphomas were sequenced (see also Supplementary Fig. 11 and Supplementary Data 1).

levels of genomic instability at V(D)J loci as compared with ATMdeficient cells and (4) $\mathrm{Rag}^{\mathrm{c} / \mathrm{c}} \mathrm{Atm}^{-/-}$mice develop aggressive T-cell lymphomas-bearing complex chromosomal translocations, amplifications and deletions involving the Tcr $\alpha / \delta$ and Igh loci, similarly to lymphomas that develop in $\mathrm{Atm}^{-/}$and $\mathrm{Rag}^{\mathrm{Cl}}$ $c_{p 53^{-1}}$ mice. We do not know yet whether the RAG and ATMDDR end-stabilization/protection function(s) requires direct biological interactions between the two complexes. 53BP $1 / \gamma \mathrm{H} 2 \mathrm{AX}$ foci accumulate at similar levels in core RAG2 pro-B cells as compared with WT pro-B cells and at higher levels in core RAG2/ XLF-deficient cells, indicating that the RAG2 C-terminus is not required for initial sensing of cleaved DNA ends (that is, the phosphorylation of $\mathrm{H} 2 \mathrm{AX}$ and accumulation of 53BP1 at RAG DSBs) by the ATM-DDR machinery. ATM and/or DNA-PKcs mediated phosphorylation of RAG1 and RAG2 proteins is not required for recombination of chromosomally integrated substrates 
in WT $v$-abl pro-B cells ${ }^{56}$; but whether such activity could contribute to the impact of ATM/RAG deficiency on $V(D) J$ recombination in the absence of XLF remains to be tested ${ }^{8}$. In response to genotoxic damage induced by irradiation, ATM phosphorylates hundreds of proteins active in different aspects of the $\mathrm{DDR}^{57}$. In that regards, ATM-DDR is likely to involve more than one pathway that could functionally compensate for XLF deficiency. In the context of $\mathrm{V}(\mathrm{D}) \mathrm{J}$ recombination, we suggest that the function of one of these pathways is to stabilize/protect DNA ends and requires the RAG proteins.

Our work raises the possibility that normal physiological antigen receptor assembly may have evolved to optimize ability of the RAG endonuclease to assist repair of generated DNA breaks within post-cleavage complexes, providing an additional layer of protection against aberrant joining, genomic instability and cell transformation. As the RAG proteins are only expressed in developing lymphocytes, such a role would necessarily overlap with the ubiquitous DNA damage response and/or cNHEJ machineries-here, we identify XLF as one component with which the RAG complex may have functionally co-evolved.

\section{Methods}

Mice. We obtained WT (Taconic), $p 53^{+/-}$(Jackson Laboratory ${ }^{58}$ ), Atm ${ }^{+/-}$ (Jackson Laboratory ${ }^{41}$ ), Rag2 ${ }^{-/-}\left(\right.$Taconic $\left.^{48}\right), K_{80}{ }^{+/-}$(Jackson Laboratory ${ }^{59}$ ), $X L F^{-1-19}, \operatorname{Rag}^{c / C 30,34}$ and $\operatorname{Rag}^{c / c} p 53^{+/-30}$ mice for this study. XLF ${ }^{-1-}$ mice were bred with p53-deficient mice to generate doubly deficient mice. Rag2 ${ }^{c / c}$ mice were bred with ATM-deficient mice to generate doubly deficient mice. Rag ${ }^{2 / c}$ were bred to $\mathrm{XLF}^{-1-}$ mice to generate doubly deficient mice. $R a g^{c / c} p 53^{+/-}$mice were bred to $\mathrm{Rag}^{c / c} \mathrm{XLF}^{-1-}$ deficient mice to generate triply deficient animals. Genotyping of these mutants was performed by PCR of tail DNA as described in the relevant references. All animal experiments were performed in accordance with the guidelines of the institutional animal care committee of Institut Pasteur/CEEA Ile-de-France-Paris1 under the protocol number 2012-0036.

Lymphocyte development. Lymphocyte development was analyzed in the thymus, bone marrow and spleen from 4 to 8-week-old mice. All single-cell suspensions were treated with Fc-blocking antibody (CD16-32, 1:200 dilution) before cell surface staining, which was performed in phosphate-buffered saline (PBS) with $2 \%$ fetal bovine serum for $30 \mathrm{~min}$ at $4{ }^{\circ} \mathrm{C}$. Bone marrow B lineage cell populations were identified based on the expression of the following markers: pro-B (B220 lo $\left.\mathrm{CD} 43^{+} \mathrm{CD} 19^{+} \mathrm{IgM}^{-}\right)$, pre-B (B220 $\left.{ }^{\text {lo }} \mathrm{CD}^{-} 3^{-} \mathrm{CD}^{+}{ }^{+} \mathrm{IgM}^{-}\right)$, immature B cells $\left(\mathrm{B} 220^{\mathrm{lo}} \mathrm{CD} 43^{-} \mathrm{CD} 19^{+} \mathrm{IgM}^{+}\right)$, recirculating B cells $\left(\mathrm{B} 220^{\text {hi }}\right.$ $\left.\mathrm{CD}^{-} 3^{-} \mathrm{CD}_{19}{ }^{+} \mathrm{IgM}^{+}\right)$. T lineage cell populations from the thymus were identified based on the expression of the following markers: double-negative (DN) cells $\left(\mathrm{CD} 4^{-} \mathrm{CD} 8^{-}\right)$, DN1 (CD4 $\left.{ }^{-} \mathrm{CD} 8^{-} \mathrm{CD} 44^{+} \mathrm{CD} 25^{-}\right)$, DN2 (CD4 ${ }^{-} \mathrm{CD} 8^{-}$ $\left.\mathrm{CD} 44^{+}{ }^{\mathrm{CD}} 25^{+}\right), \mathrm{DN} 3\left(\mathrm{CD} 4^{-} \mathrm{CD} 8^{-} \mathrm{CD} 44^{-} \mathrm{CD} 25^{+}\right), \mathrm{DN} 4\left(\mathrm{CD} 4^{-} \mathrm{CD} 8{ }^{-}\right.$ $\left.\mathrm{CD} 44^{-} \mathrm{CD} 25^{-}\right)$, double-positive (DP) cells $\left(\mathrm{CD} 4^{+} \mathrm{CD} 8^{+}\right)$and single-positive (SP) cells $\left(\mathrm{CD} 4{ }^{+} \mathrm{CD} 8{ }^{-}\right.$and $\left.\mathrm{CD} 4^{-} \mathrm{CD} 8^{+}\right)$. Lymphocytes from the spleen were identified based on the expression of the following markers: B cells $\left(\mathrm{CD} 19^{+} \mathrm{IgM}^{+}\right)$ and $\mathrm{T}$ cells $\left(\mathrm{CD}^{+}{ }^{+} \mathrm{TCR} \beta^{+}\right)$. The following antibodies were used for cell surface staining: anti-B220 (RA3-6B2, 1:200 dilution), anti-CD43 (S7, 1:150 dilution), CD19 (1D3, 1:200 dilution), anti-IgM (R6-60.2, 1:150 dilution), anti-IgD (11-26c.2a, 1:200 dilution), anti-c-Kit (2B8, 1:300 dilution), anti-CD4 (RM4-5, 1:200 dilution), antiCD8a (53-6.7, 1:200 dilution), anti-CD3e (145-2C11, 1:200 dilution), anti-CD44 (IM7, 1:200 dilution), anti-CD25 (PC61, 1:200 dilution) and anti-TCR $\beta$ (H57-597, 1:200 dilution). All antibodies were purchased from BD Biosciences except anti-TCR $\beta$, which was from eBiosciences. Flow cytometry was performed on a FACS Canto II (BD Bioscience) and data were analysed using FlowJo (TreeStar).

In vitro culture of B-cell progenitors. Freshly isolated bone marrow cells from 2-4 mice (4-8 weeks old) were pooled and depleted of $\operatorname{IgM}^{+}$cells by magnetic separation using IgM microbeads (Miltenyi). IgM ${ }^{-}$cells were then incubated with CD19 microbeads (Miltenyi) and enriched for $\mathrm{CD}_{19}{ }^{+}$cells. Bone marrow $\mathrm{CD}_{19}{ }^{+} \mathrm{IgM}^{-}$cells were cultured for 3-4 days in complete Opti-MEM supplemented with IL-7 (50 $\left.\mathrm{ng} \mathrm{ml}^{-1}\right)$, SCF $\left(50 \mathrm{ng} \mathrm{ml}^{-1}\right)$ and Flt3L $\left(50 \mathrm{ng} \mathrm{ml}^{-1}\right)$ to stimulate proliferation of pro-B cells before metaphase preparation.

Generation of $\boldsymbol{v}$ - $\boldsymbol{a b}$ / transformed pro-B cell lines. Total bone marrow from 3-5-week-old mice of each genotype was cultured and infected with a retrovirus encoding $v$-abl kinase to generate immortalized pro-B cell lines ${ }^{60} . v$ - $a b l$ transformed pro-B cell lines were then transduced with pMSCV-Bcl2-puro retrovirus ${ }^{61}$ to protect them from $v$-abl kinase inhibitor-induced cell death (Supplementary Fig. 5a).
V(D)J recombination assays. The $\mathrm{pMX}-\mathrm{INV}$ or $\mathrm{pMX}-\mathrm{DEL} \mathrm{CJ}^{\mathrm{CJ}}$ substrate was introduced in pro-B cell lines through retroviral infection and cells that had integrated the recombination substrate were enriched based on hCD4 expres $\operatorname{sion}^{7,34}$. For V(D)J recombination assay, $v$-abl transformed $B c l 2 /$ pMX-INV infected pro-B cells $\left(10^{6}\right.$ per $\left.\mathrm{ml}\right)$ were treated with $3 \mu \mathrm{M}$ of the $v$-abl kinase inhibitor STI571 (Novartis) or $0.3 \mu \mathrm{M}$ of the STI571-analogous $v$-abl kinase inhibitor PD180970 (Sigma) and assayed for rearrangement by FACS analysis of GFP expression or Southern blotting at 0,72 or $96 \mathrm{~h}$. In some experiments, the ATM kinase inhibitor KU55933 was added at $15 \mu \mathrm{M}$ together with PD180970 or STI571 (named ABLki). For FACS analysis, V(D)J recombination efficiency was scored as the percentage of GFP positive cells among hCD4-positive cells (human CD4-PE, Miltenyi, 1:20 dilution). For ABLki release experiments, cells were collected, washed and cultured without ABLki for 3-4 days before metaphases preparation.

Southern blot. $30 \mu \mathrm{g}$ of gDNA from untreated, ABLki-treated and ABLki/ATMki treated pro-B cell lines were digested overnight with EcoRV for pMX-DEL ${ }^{\mathrm{CJ}}$, EcoRV or EcoRV/NcoI for pMX-INV and SacI/EcoRI for endogenous Igk locus analysis. Digested gDNA samples were run overnight on an agarose gel, denatured by incubating the gel with $0.5 \mathrm{M} \mathrm{NaOH} / 0.6 \mathrm{M} \mathrm{NaCl}$ for $1 \mathrm{~h}$, and then transferred overnight on a Zeta-Probe GT nylon membrane (Biorad). DNA was cross-linked on the membrane using a UV Cross-linker CL-508 (Uvitec Cambridge). Blots were incubated at $42{ }^{\circ} \mathrm{C}$ in pre-hybridization buffer for at least $1 \mathrm{~h}$ and then overnight in hybridization buffer containing a $32^{\mathrm{P}}$-CTP labelled probe: the C4 probe for pMX-INV and pMX-DEL ${ }^{\text {CJ } 7,21}$ and the JkIII probe for Igk locus ${ }^{7,62}$. Blots were washed in $2 \mathrm{XSSC} / 0.1 \%$ SDS at $65^{\circ} \mathrm{C}$ and exposed to a Storage Phosphor Screen (GE Healthcare) for 2-5 days. The screen was then scanned using a Storm 860 PhosporImager (Molecular Dynamics).

PCR analysis of V(D)J recombination products. pMX-DEL ${ }^{\mathrm{CJ}} \mathrm{CJ}$ s were amplified using pC (5'-GCACGAAGTCTTGAGACCT-3') and IRES-REV5 (5'-CTCGACT AAACACATGTAAAGC-3') oligonucleotides as previously described ${ }^{7,49}$.

Oligonucleotide IR4 (5'-CCCTTGTTGAATACGCTTG-3') was used as a probe for pMX-DEL ${ }^{C J}$ CJs. Il2 gene was amplified using IMR42 (5'-CTAGGCCACAG AATTGAAAGATCT- $\left.3^{\prime}\right)$ and IMR43 (5'-GTAGGTGGAAATTCTAGCATGA TGC- $3^{\prime}$ ) primers and was used as loading control. pMX-DEL ${ }^{\mathrm{CJ}}$ CJs were cloned using TOPO TA Cloning kit (Life Technologies) following manufacturer's instructions and analyzed by Sanger Sequencing using T3 (5'-AATTAACCCTCA CTAAAGGGA-3') and T7 (5'-TAATACGACTCACTATAGG-3') primers. Endogenous $V \kappa_{6-23} / J k_{1}$ CJs and HJs were amplified as previously described ${ }^{7}$. A total of $500 \mathrm{ng}$ of genomic DNA was amplified using pkJa (5'-GGAGAGTGCCAGA ATCTGGTTTCAG- $\left.3^{\prime}\right)$ and pk6a (5'-TGCATGTCAGAGGGCACAACTG-3') primers for $\mathrm{HJ}$ and pkJa2 (5'-GCCACAGACATAGACAACGGAA- $\left.3^{\prime}\right)$ and pk6d ( $5^{\prime}$-GAAATACATCAGACCAGCATGG-3') primers for CJ. Serial 4-fold dilutions of this reaction were amplified using pkJa and pk6b $\left(5^{\prime}\right.$-CTACCAAACTTTGCA ACACACAGGC- $\left.3^{\prime}\right)$ primers for HJ and pkJa2 and pk6c (5'-GTTGCTGTGGTTG TCTGGTG- $3^{\prime}$ ) primers for CJ.

Metaphase preparation. Metaphases were prepared using standard procedures ${ }^{30}$ Briefly, cells were incubated with colcemid $\left(0.03 \mu \mathrm{g} \mathrm{ml}^{-1}\right.$, Life technologies, KaryoMAX Colcemid Solution) for $3-4 \mathrm{~h}$ at $37^{\circ} \mathrm{C}$. Then, cells were collected and incubated in $0.075 \mathrm{M} \mathrm{KCl}$ for $10 \mathrm{~min}$ at $37^{\circ} \mathrm{C}$, fixed in fixative solution $(75 \%$ methanol $/ 25 \%$ acetic acid) and washed three times in the fixative. Cell suspension was dropped onto humid slides and air-dried for further analysis.

DNA-FISH probes. BAC probes RP24-134G24 (5' Igh C), RP24-386J17 (3' Igh V), RP24-243E11 (5' Igk V), RP23-341D5 (3' Igk C) and RP24-307D14 (c-myc) were directly labelled by nick translation with ChromaTide Alexa Fluor 488- or 594-5dUTP (Life technologies), or Cy3-dUTP (GE Healthcare), as previously described $^{63}$. Nick translation reaction was optimized to get a DNA smear between 100 and $600 \mathrm{bp}$. Labelled BAC probes were purified using Illustra MicroSpin G-50 Columns (GE Healthcare). A total of $600 \mathrm{ng}$ of each locus-specific BAC probes were pooled and precipitated with mouse Cot1 DNA and Salmon Sperm DNA (Life Technologies). Probes were then re-suspended in hybridization buffer ( $10 \%$ dextran sulphate, $5 \times$ Denharts solution, $50 \%$ formamide), denatured for $5 \mathrm{~min}$ at $95^{\circ} \mathrm{C}$ and pre-annealed for $30-45 \mathrm{~min}$ at $37^{\circ} \mathrm{C}$. XCyting Mouse Chromosome 6, 12 or 14 (Red or Orange) paints from MetaSystems were denatured for $5 \mathrm{~min}$ at $95^{\circ} \mathrm{C}$ and mixed with BAC probes just before hybridization.

DNA FISH on metaphase spreads. Slides were treated with RNase A for $40 \mathrm{~min}$, dehydrated in 70, 90 and $100 \%$ ethanol for 3 min each, denatured in $70 \%$ formamide $/ 2 \times$ SSC for $3 \mathrm{~min}$ at $77^{\circ} \mathrm{C}$, dehydrated again in cold ethanol series, and hybridized with probes $\mathrm{o} / \mathrm{n}$ at $37^{\circ} \mathrm{C}$ in a humid chamber. The next day, slides were washed three times in $50 \%$ formamide $/ 0.5 \times$ SSC for 5 min each at $37^{\circ} \mathrm{C}$ and twice in $0.5 \times$ SSC for $10 \mathrm{~min}$ each at $37^{\circ} \mathrm{C}$. Finally, slides were mounted in ProLong Gold (Life Technologies) containing 49,6-diamidino-2-phenylindole (DAPI) to counterstain total DNA. Metaphases were imaged using a ZEISS 
AxioImager.Z2 microscope and the Metafer automated capture system (MetaSystems), and counted manually.

Immuno-DNA FISH on interphase nuclei. After 3d treatment with PD180970, pro-B cell lines were adhered to poly-L lysine-coated coverslips and stained as previously described ${ }^{63}$ with minor changes. Cells were fixed with $4 \%$ paraformaldehyde/PBS for $10 \mathrm{~min}$ at room temperature (RT) and permeabilized for 5 min with $0.4 \%$ Triton/PBS on ice. Immunofluorescence was performed after $30 \mathrm{~min}$ blocking in $3 \%$ bovine serum albumin/PBS, with a primary antibody against 53BP1 (NB100-304SS, 1:400 dilution, Novus Biologicals) and a secondary goatanti-rabbit antibody (Alexa Fluor 594, 1:800 dilution; Life Technologies) in blocking solution, each for $1 \mathrm{~h}$ at RT. For co-localization experiments with $\gamma \mathrm{H} 2 \mathrm{AX}$, FITC-labelled antibody against phosphorylated serine-139 of $\mathrm{H} 2 \mathrm{AX}(\gamma-\mathrm{H} 2 \mathrm{AX}-\mathrm{FITC}$ clone JBW301, 1:400 dilution, Millipore) was added at the secondary staining step. Cells were rinsed three times in $0.5 \%$ bovine serum albumin/PBS, and post-fixed in $4 \%$ paraformaldehyde/PBS for $10 \mathrm{~min}$ at RT. Cells for both DNA FISH and immuno-FISH were then incubated with $0.01 \mathrm{mg} \mathrm{ml}^{-1}$ RNaseA for at least $1 \mathrm{~h}$ at $37^{\circ} \mathrm{C}$ and permeabilized in $0.7 \%$ Triton $\mathrm{X}-100 / 0.1 \mathrm{M} \mathrm{HCl}$ for $10 \mathrm{~min}$ on ice. Cells were then denatured with $2 \mathrm{~N} \mathrm{HCl}$ for $30 \mathrm{~min}$ at $\mathrm{RT}$, rinsed three times in iced-cold PBS and hybridized overnight at $37^{\circ} \mathrm{C}$ with $0.6-1 \mu \mathrm{g}$ of $\operatorname{IgkC}$ probe (coverslips were sealed onto slides with rubber cement). The next day, cells were rinsed in $2 \times$ SSC at $37^{\circ} \mathrm{C}$, then in $2 \times$ SSC at RT and finally in $1 \times$ SSC at RT, for 45 min each. Finally slides were mounted in DAPI/Antifade reagent (MetaSystems). Cells were imaged in $3 \mathrm{D}$ ( $9 \mathrm{Z}$ stacks of $0.5 \mu \mathrm{m})$ using a Zeiss AxioImager Z2 microscope and the Metacyte automated capture system (Metasystems). FISH signals were counted using a custom Metacyte classifier. $>10,000$ nuclei were counted for each genotype (see Supplementary Table 1 for details).

Characterization of tumour cells. Lymphoid tumours were analysed by flow cytometry with antibodies against surface B-cell (anti-B220 (RA3-6B2, 1:200 dilution), anti-CD43 (S7, 1:150 dilution), CD19 (1D3, 1:200 dilution), anti-IgM (R6-60.2, 1:150 dilution), anti-IgD (11-26c.2a, 1:200 dilution), anti-c-Kit (2B8, 1:300 dilution)) and T-cell markers (anti-CD4 (RM4-5, 1:200 dilution), anti-CD8a (53-6.7, 1:200 dilution), anti-CD3e (145-2C11, 1:200 dilution), anti-CD44 (IM7, 1:200 dilution), anti-CD25 (PC61, 1:200 dilution), and anti-TCR $\beta$ (H57-597, 1:200 dilution)). Flow cytometry was performed on a FACS Canto II (BD Bioscience) and data were analysed using FlowJo (TreeStar). Tumour cells were cultured for $2 \mathrm{~h}$ in complete RPMI medium before metaphases preparation. Metaphases spreads were stained with $21 \times$ Mouse, Multicolour Painting mFISH Probe Kit (MetaSystems), which was prepared following supplier's instructions. Slides were mounted in $90 \%$ DAPI/Antifade reagent (MetaSystems)/10\% ProLong Gold (Life Technologies). Metaphases were imaged using a ZEISS AxioImager.Z2 microscope and the Metafer automated capture system (MetaSystems). Karyotyping was performed using Isis software (MetaSystems)

Statistics. For lymphocyte development, V(D)J recombination and 53BP1 focus formation assays on $v$-abl pro-B cells, statistical analyses were performed using the non-parametric Mann-Whitney $U$-test. For DNA FISH experiments, Fisher exact tests were used to determine statistical significance (see Supplementary Tables 3 and 4 for details). Prism GraphPad Software was utilized for generating Kaplan-Meier mouse tumour-free survival plots and statistical analysis of survival and tumour onset (log-rank test). In all statistical tests, $P$ values $<0.05$ were taken to be significant $\left(0.01 \leq P<0.05^{*}\right.$ significant; $0.001 \leq P<0.01{ }^{* *}$ very significant; $P<0.001^{* * *}$ highly significant).

Whole-genome sequencing. The $3 \mathrm{~B}$-cell lymphomas that were sequenced originate from the lymph nodes of three different $\mathrm{Rag}^{\mathrm{c} / \mathrm{c}} \mathrm{XLF} \mathrm{F}^{-/-} \mathrm{p53^{-/- }}$ mice: 13111 (female, 9.3 week old), 14189 (male, 9.1 week old), 14821 (male, 11.1 week old).

Genomic DNA was prepared from single-cell suspension of tumour lymph nodes using Wizard Genomic DNA purification Kit (Promega). Whole-genome library was generated according to the Paired-End Sample Preparation kit (Illumina) protocol. A total of 100 nucleotides paired-end sequencing was performed on an Illumina Genome Analyzer HiSeq 2000 instrument.

Short read sequences were mapped to the reference mouse genome ( $\mathrm{mml}$, Ensembl74) using the Burrows-Wheeler Aligner version 0.7.4 (BWA ${ }^{64}$ ) algorithm with default parameters except the option -q 25 for read trimming. Duplicate reads were removed using the function MarkDuplicates from Picard tools and a filtering for uniquely mapped reads was performed. We obtained 385 millions uniquely mapped paired-end reads corresponding to $28 \times$ coverage of the mouse genome.

Structural variations (SVs) were predicted by SVDetect ${ }^{65}$ version $\mathrm{r} 0.8 \mathrm{~b}$, which uses discordant mapped read pairs provided by the aligner to indicate potential genomic variations from the reference. Mean insert size and standard deviation were computed using the function CollectInsertSizeMetrics from Picard tools. Discordant read pairs with low BWA mapping quality scores (the threshold was set to 23) were removed. SVDetect links2compare function was used for comparison of the tumour and control samples, and we disabled the option for comparing only links sharing the same SV type. We removed SVs identified in the genomes of control samples with at least one read pair. We used four genomes representative of our in-laboratory mouse strains for controls. We removed SVs supported with $<4$ read pairs. We also removed SVs found in highly repeated regions, by requiring $<80$ or $50 \%$ overlap with RepeatMasker and simple repeats tracks respectively (UCSC). The overlap with repeats was computed with BEDTools. Circos ${ }^{66}$ plot was used to visualize chromosomal rearrangements and copy number variations. We used Socrates ${ }^{67}$ and Delly ${ }^{68}$ version 0.5 .6 to identify breakpoints of SVs with singlenucleotide resolution and Socrates to predict micro-homologies and untemplated sequences at breakpoints.

Copy number variants were detected with Control-FREEC algorithm, which uses coverage depth differences to identify amplified or deleted regions ${ }^{69}$. Read count is calculated in sliding windows (window size was set to $50,000 \mathrm{bp}$ ) and control sample was used to normalize read count in the tumour sample. Copy number profiles per chromosome were visualized using $\mathrm{R}$.

\section{References}

1. Bassing, C. H., Swat, W. \& Alt, F. W. The mechanism and regulation of chromosomal V(D)J recombination. Cell 109(Suppl): S45-S55 (2002).

2. Schatz, D. G. \& Swanson, P. C. V(D)J recombination: mechanisms of initiation. Annu. Rev. Genet. 45, 167-202 (2011).

3. Deriano, L. \& Roth, D. B. Modernizing the nonhomologous end-joining repertoire: alternative and classical NHEJ share the stage. Annu. Rev. Genet. 47, 433-455 (2013).

4. Revy, P., Buck, D., le Deist, F. \& de Villartay, J. P. The repair of DNA damages/ modifications during the maturation of the immune system: lessons from human primary immunodeficiency disorders and animal models. $A d v$. Immunol. 87, 237-295 (2005).

5. Rooney, S., Chaudhuri, J. \& Alt, F. W. The role of the non-homologous endjoining pathway in lymphocyte development. Immunol. Rev. 200, 115-131 (2004)

6. Helmink, B. A. \& Sleckman, B. P. The response to and repair of RAG-mediated DNA double-strand breaks. Annu. Rev. Immunol. 30, 175-202 (2012).

7. Bredemeyer, A. L. et al. ATM stabilizes DNA double-strand-break complexes during V(D)J recombination. Nature 442, 466-470 (2006).

8. Kumar, V., Alt, F. W. \& Oksenych, V. Functional overlaps between XLF and the ATM-dependent DNA double strand break response. DNA Repair (Amst.) 16, 11-22 (2014).

9. Buck, D. et al. Cernunnos, a novel nonhomologous end-joining factor, is mutated in human immunodeficiency with microcephaly. Cell 124, 260-262 (2006).

10. Ahnesorg, P., Smith, P. \& Jackson, S. P. XLF interacts with the XRCC4-DNA ligase IV complex to promote DNA nonhomologous end-joining. Cell 124, 301-313 (2006).

11. Li, Y. et al. Crystal structure of human XLF/Cernunnos reveals unexpected differences from XRCC4 with implications for NHEJ. Embo J. 27, 290-300 (2008).

12. Andres, S. N., Modesti, M., Tsai, C. J., Chu, G. \& Junop, M. S. Crystal structure of human XLF: a twist in nonhomologous DNA end-joining. Mol. Cell 28, 1093-1101 (2007).

13. Callebaut, I. et al. Cernunnos interacts with the XRCC4 x DNA-ligase IV complex and is homologous to the yeast nonhomologous end-joining factor Nej1. J. Biol. Chem. 281, 13857-13860 (2006).

14. Reid, D. A. et al. Organization and dynamics of the nonhomologous end-joining machinery during DNA double-strand break repair. Proc. Natl Acad. Sci. USA 112, E2575-E2584 (2015).

15. Ropars, V. et al. Structural characterization of filaments formed by human Xrcc4-Cernunnos/XLF complex involved in nonhomologous DNA end-joining. Proc. Natl Acad. Sci. USA 108, 12663-12668 (2011).

16. Hammel, M. et al. XRCC4 protein interactions with XRCC4-like factor (XLF) create an extended grooved scaffold for DNA ligation and double strand break repair. J. Biol. Chem. 286, 32638-32650 (2011).

17. Riballo, E. et al. XLF-Cernunnos promotes DNA ligase IV-XRCC4 re-adenylation following ligation. Nucleic Acids Res. 37, 482-492 (2009).

18. Tsai, C. J., Kim, S. A. \& Chu, G. Cernunnos/XLF promotes the ligation of mismatched and noncohesive DNA ends. Proc. Natl Acad. Sci. USA 104, 7851-7856 (2007).

19. Vera, G. et al. Cernunnos deficiency reduces thymocyte lifespan and alters the T cell repertoire in mice and humans. Mol. Cell. Biol. 33, 701-711 (2012).

20. Li, G. et al. Lymphocyte-specific compensation for XLF/cernunnos end-joining functions in V(D)J recombination. Mol. Cell 31, 631-640 (2008).

21. Zha, S. et al. ATM damage response and XLF repair factor are functionally redundant in joining DNA breaks. Nature 469, 250-254 (2011).

22. Dudley, D. D., Chaudhuri, J., Bassing, C. H. \& Alt, F. W. Mechanism and control of $\mathrm{V}(\mathrm{D}) \mathrm{J}$ recombination versus class switch recombination: similarities and differences. Adv. Immunol. 86, 43-112 (2005).

23. Roth, D. B. Restraining the V(D)J recombinase. Nat. Rev. Immunol. 3, 656-666 (2003).

24. Tsai, C. L., Drejer, A. H. \& Schatz, D. G. Evidence of a critical architectura function for the RAG proteins in end processing, protection, and joining in V(D)J recombination. Genes Dev. 16, 1934-1949 (2002). 
25. Huye, L. E., Purugganan, M. M., Jiang, M. M. \& Roth, D. B. Mutational analysis of all conserved basic amino acids in RAG-1 reveals catalytic, step arrest, and joining-deficient mutants in the V(D)J recombinase. Mol. Cell Biol. 22, 3460-3473 (2002).

26. Yarnall Schultz, H., Landree, M. A., Qiu, J. X., Kale, S. B. \& Roth, D. B. Joining-deficient RAG1 mutants block V(D)J recombination in vivo and hairpin opening in vitro. Mol. Cell 7, 65-75 (2001).

27. Qiu, J. X., Kale, S. B., Yarnell Schultz, H. \& Roth, D. B. Separation-of-function mutants reveal critical roles for RAG2 in both the cleavage and joining steps of V(D)J recombination. Mol. Cell 7, 77-87 (2001).

28. Roth, D. B. V(D)J recombination: mechanism, errors, and fidelity. Microbiol. Spectr. 2, MDNA3-0041-2014 (2014).

29. Coussens, M. A. et al. RAG2's acidic hinge restricts repair-pathway choice and promotes genomic stability. Cell Rep. 4, 870-878 (2013).

30. Deriano, L. et al. The RAG2 C-terminus suppresses genomic instablity and lymphomagenesis. Nature 471, 119-123 (2011).

31. Corneo, B. et al. Rag mutations reveal robust alternative end joining. Nature 449, 483-486 (2007).

32. Lee, G. S., Neiditch, M. B., Salus, S. S. \& Roth, D. B. RAG proteins shepherd double-strand breaks to a specific pathway, suppressing error-prone repair, but RAG nicking initiates homologous recombination. Cell 117, 171-184 (2004).

33. Gigi, V. et al. RAG2 mutants alter DSB repair pathway choice in vivo and illuminate the nature of 'alternative NHEJ'. Nucleic Acids Res. 42, 6352-6364 (2014).

34. Liang, H. E. et al. The 'dispensable' portion of RAG2 is necessary for efficient $\mathrm{V}$-to-DJ rearrangement during $\mathrm{B}$ and $\mathrm{T}$ cell development. Immunity 17, 639-651 (2002).

35. Jones, J. M. \& Simkus, C. The roles of the RAG1 and RAG2 'non-core' regions in $\mathrm{V}(\mathrm{D}) \mathrm{J}$ recombination and lymphocyte development. Arch. Immunol. Ther. Exp. (Warsz) 57, 105-116 (2009).

36. Curry, J. D. \& Schlissel, M. S. RAG2's non-core domain contributes to the ordered regulation of V(D)J recombination. Nucleic Acids Res. 36, 5750-5762 (2008).

37. Talukder, S. R., Dudley, D. D., Alt, F. W., Takahama, Y. \& Akamatsu, Y. Increased frequency of aberrant $\mathrm{V}(\mathrm{D}) \mathrm{J}$ recombination products in core RAG-expressing mice. Nucleic Acids Res. 32, 4539-4549 (2004).

38. Akamatsu, Y. et al. Deletion of the RAG2 C terminus leads to impaired lymphoid development in mice. Proc. Natl Acad. Sci. USA 100, 1209-1214 (2003).

39. Sekiguchi, J. A., Whitlow, S. \& Alt, F. W. Increased accumulation of hybrid $\mathrm{V}(\mathrm{D}) \mathrm{J}$ joins in cells expressing truncated versus full-length RAGs. Mol. Cell 8, 1383-1390 (2001).

40. Zha, S. et al. ATM-deficient thymic lymphoma is associated with aberrant tcrd rearrangement and gene amplification. J. Exp. Med. 207, 1369-1380 (2010).

41. Barlow, C. et al. Atm-deficient mice: a paradigm of ataxia telangiectasia. Cell 86, 159-171 (1996)

42. Rooney, S. et al. Leaky scid phenotype associated with defective V(D)J coding end processing in Artemis-deficient mice. Mol. Cell 10, 1379-1390 (2002).

43. Gu, Y. et al. Growth retardation and leaky SCID phenotype of Ku70-deficient mice. Immunity 7, 653-665 (1997).

44. Muljo, S. A. \& Schlissel, M. S. A small molecule Abl kinase inhibitor induces differentiation of Abelson virus-transformed pre-B cell lines. Nat. Immunol. 4, 31-37 (2003).

45. Taccioli, G. E. et al. Ku80: Product of the XRCC5 gene and its role in DNA repair and V(D)J recombination. Science 265, 1442-1445 (1994).

46. Panier, S. \& Boulton, S. J. Double-strand break repair: 53BP1 comes into focus. Nat. Rev. Mol. Cell. Biol. 15, 7-18 (2014).

47. Chen, H. T. et al. Response to RAG-mediated VDJ cleavage by NBS1 and gamma-H2AX. Science 290, 1962-1965 (2000).

48. Shinkai, Y. et al. RAG-2-deficient mice lack mature lymphocytes owing to inability to initiate V(D)J rearrangement. Cell 68, 855-867 (1992).

49. Helmink, B. A. et al. H2AX prevents CtIP-mediated DNA end resection and aberrant repair in G1-phase lymphocytes. Nature 469, 245-249 (2011)

50. Jankovic, M., Nussenzweig, A. \& Nussenzweig, M. C. Antigen receptor diversification and chromosome translocations. Nat. Immunol. 8, 801-808 (2007).

51. Zhu, C. et al. Unrepaired DNA breaks in p53-deficient cells lead to oncogenic gene amplification subsequent to translocations. Cell 109, 811-821 (2002).

52. Roy, S. et al. XRCC4's interaction with XLF is required for coding (but not signal) end joining. Nucleic Acids Res. 40, 1684-1694 (2012).

53. Zha, S., Alt, F. W., Cheng, H. L., Brush, J. W. \& Li, G. Defective DNA repair and increased genomic instability in Cernunnos-XLF-deficient murine ES cells. Proc. Natl Acad. Sci. USA 104, 4518-4523 (2007).

54. Gu, J., Lu, H., Tsai, A. G., Schwarz, K. \& Lieber, M. R. Single-stranded DNA ligation and XLF-stimulated incompatible DNA end ligation by the XRCC4-DNA ligase IV complex: influence of terminal DNA sequence. Nucleic Acids Res. 35, 5755-5762 (2007)

55. Tubbs, A. T. et al. KAP-1 promotes resection of broken DNA ends not protected by gamma-H2AX and 53BP1 in G(1)-phase lymphocytes. Mol. Cell Biol. 34, 2811-2821 (2014).
56. Gapud, E. J., Lee, B. S., Mahowald, G. K., Bassing, C. H. \& Sleckman, B. P. Repair of chromosomal RAG-mediated DNA breaks by mutant RAG proteins lacking phosphatidylinositol 3-like kinase consensus phosphorylation sites. J. Immunol. 187, 1826-1834 (2011).

57. Matsuoka, S. et al. ATM and ATR substrate analysis reveals extensive protein networks responsive to DNA damage. Science 316, 1160-1166 (2007).

58. Jacks, T. et al. Tumour spectrum analysis in p53-mutant mice. Curr. Biol. 4, 1-7 (1994).

59. Nussenzweig, A. et al. Requirement for Ku80 in growth and immunoglobulin V(D)J recombination. Nature 382, 551-555 (1996).

60. Rosenberg, N., Baltimore, D. \& Scher, C. D. In vitro transformation of lymphoid cells by Abelson murine leukemia virus. Proc. Natl Acad. Sci. USA 72, 1932-1936 (1975).

61. Kollmann, K. et al. c-JUN promotes BCR-ABL-induced lymphoid leukemia by inhibiting methylation of the $5^{\prime}$ region of Cdk6. Blood 117, 4065-4075 (2011).

62. Lee, B. S. et al. Functional intersection of ATM and DNA-dependent protein kinase catalytic subunit in coding end joining during $\mathrm{V}(\mathrm{D}) \mathrm{J}$ recombination. Mol. Cell. Biol. 33, 3568-3579 (2013).

63. Chaumeil, J., Micsinai, M. \& Skok, J. A. Combined immunofluorescence and DNA FISH on 3D-preserved interphase nuclei to study changes in 3D nuclear organization. J. Vis. Exp. 3, e50087 (2013).

64. Li, H. \& Durbin, R. Fast and accurate short read alignment with BurrowsWheeler transform. Bioinformatics 25, 1754-1760 (2009).

65. Zeitouni, B. et al. SVDetect: a tool to identify genomic structural variations from paired-end and mate-pair sequencing data. Bioinformatics 26, 1895-1896 (2010).

66. Krzywinski, M. et al. Circos: an information aesthetic for comparative genomics. Genome Res. 19, 1639-1645 (2009).

67. Schroder, J. et al. Socrates: identification of genomic rearrangements in tumour genomes by re-aligning soft clipped reads. Bioinformatics 30, 1064-1072 (2014)

68. Rausch, T. et al. DELLY: structural variant discovery by integrated paired-end and split-read analysis. Bioinformatics 28, i333-i339 (2012).

69. Boeva, V. et al. Control-FREEC: a tool for assessing copy number and allelic content using next-generation sequencing data. Bioinformatics 28, 423-425 (2012).

\section{Acknowledgements}

We thank Fred Alt and his laboratory members, especially Richard Frock, Jiazhi Hu and Hai Vu Nguyen, for discussion, advices and precious help with Southern blotting experiments. We thank Christiane Bouchier, Laurence Ma and members of the Institut Pasteur Genopole for help with WGS and Shauna Katz for editing the manuscript. J.-P.d.V. laboratory is supported by the INSERM, ANR and Ligue Nationale contre le Cancer (Equipe Labellisée La Ligue). L.D. laboratory is supported by the Institut Pasteur, the CNRS, the Fondation pour la Recherche Médicale, the Ville de Paris, as well as by the European Research Council under the ERC starting grant agreement \# 310917.

\section{Author contributions}

L.D., J.-P.d.V. and C.L. planned the experiments and wrote the manuscript. C.L. performed all experiments with contribution from V.A., G.V. and M.B.-F. for characterization of the $\mathrm{Rag}^{\mathrm{c} / \mathrm{C}} \mathrm{XLF}^{-/-}$mice, J.-P.d.V. for Bcl2/pMX-INV infection, flow cytometry and PCR analysis of recombination in v-abl pro-B cell lines, and M.B.-F. for cytogenetic analysis, mouse survival analysis and mouse tumour phenotyping. V.M. performed whole-genome sequencing analysis. L.D. and C.L. generated $v$-abl immortalized pro-B cell lines. J.-P.d.V. provided XLF-deficient mice. C.L. and M.B.-F. generated all mouse crosses except the initial $\mathrm{Rag}^{\mathrm{c} / \mathrm{c}} \mathrm{Atm}^{+/-}$colony that was established by L.D. in D.B.R. laboratory. P.R. and D.B.R. commented the manuscript. All the authors read and approved the manuscript.

\section{Additional information}

Accession codes: The whole genome sequencing data from the lymphomas has been deposited at the Sequencing Read Archive under accession code SRP067544.

Supplementary Information accompanies this paper at http://www.nature.com/ naturecommunications

Competing financial interests: The authors declare no competing financial interests.

Reprints and permission information is available online at http://npg.nature.com/ reprintsandpermissions/

How to cite this article: Lescale, C. et al. RAG2 and XLF/Cernunnos interplay reveals a novel role for the RAG complex in DNA repair. Nat. Commun. 7:10529 doi: 10.1038/ncomms10529 (2016).

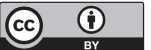

This work is licensed under a Creative Commons Attribution 4.0 International License. The images or other third party material in this article are included in the article's Creative Commons license, unless indicated otherwise in the credit line; if the material is not included under the Creative Commons license, users will need to obtain permission from the license holder to reproduce the material. To view a copy of this license, visit http://creativecommons.org/licenses/by/4.0/ 